\title{
Plate tectonics and mantle controls on plume dynamics
}

Maëlis Arnould ${ }^{\mathrm{a}, \mathrm{b}, \mathrm{c}, \mathrm{d}, *}$, Nicolas Coltice ${ }^{\mathrm{a}}$, Nicolas Flament ${ }^{\mathrm{e}}$, Claire Mallard ${ }^{\mathrm{c}}$

${ }^{a}$ Laboratoire de Géologie, École Normale Supérieure, CNRS UMR 8538, PSL Research University, 24 rue Lhomond, 75005 Paris, France

${ }^{b}$ Université de Lyon, École Normale Supérieure de Lyon, Université Claude Bernard, Laboratoire de Géologie de Lyon, Terre, Planètes, Environnement, CNRS UMR 5276, 2 rue Raphaël Dubois, 69622 Villeurbanne, France

${ }^{c}$ EarthByte Group, School of Geosciences, The University of Sydney, NSW 2006, Australia

${ }^{d}$ Now at Centre for Earth Evolution and Dynamics, Department of Geosciences, University of Oslo, 0371 Oslo, Norway

${ }^{e}$ GeoQuEST Research Centre, School of Earth, Atmospheric and Life Sciences, University of Wollongong, Northfields Avenue, Wollongong, NSW 2522, Australia

\section{Abstract}

Mantle plumes provide valuable information about whole Earth convection: they originate at the core-mantle boundary, cross Earth's mantle and interact with the lithosphere. For instance, it has been proposed that the mobility/stability of plumes depends on plume intrinsic properties, on how slabs interact with the basal boundary layer, on mantle flow, or on their proximity to mid-ocean ridges.

Here, we use 3D-spherical models of mantle convection generating selfconsistent plate-like behaviour to investigate the mechanisms linking tectonics and mantle convection to plume dynamics. Our models produce fullydynamic mantle plumes that rise vertically with deflection $<10^{\circ}$ and present excess temperatures, rising speeds, buoyancy and heat fluxes comparable to

\footnotetext{
* Corresponding author.

Email address: maelis.arnould@geo.uio.no (Maëlis Arnould)
} 
observations. In the absence of plate tectonics, plumes are stable and their lifetime exceeds hundreds of million years. With plate tectonics, plumes are more mobile, and we identify four physical mechanisms controlling their stability. 1/ Fixed plumes are located at saddle points of basal mantle flow. 2/ Plumes moving at speeds between $0.5-1 \mathrm{~cm} \mathrm{yr}^{-1}$ are slowly entrained by passive mantle flow. 3/ Fast plume motions between $2-5 \mathrm{~cm} \mathrm{yr}^{-1}$ lasting several tens of million years are caused by slab push. 4/ Plumes occasionally drift at speeds $>5 \mathrm{~cm} \mathrm{yr}^{-1}$ over $<10 \mathrm{Myr}$ through plume merging. We do not observe systematic anchoring of plumes to mid-oceanic ridges. Independent of the presence of a dense basal layer, plate-like regimes decrease the lifetime of plumes compared to stagnant-lid models. Plume age, temperature excess or buoyancy flux are not diagnostic of plume lateral speed. The fraction of plumes moving by less than $0.5 \mathrm{~cm} \mathrm{yr}^{-1}$ is $>25 \%$, which suggests that fixed hotspot reference frames can be defined from carefully selected hotspot tracks.

Keywords: Mantle plumes, plume drift, numerical modelling, mantle convection, plate-like tectonics

\section{1. Introduction}

2 Since Morgan (1972) linked deep mantle plumes to tectonics motions, the 3 combination of seismology, petrology and geophysics have led to the charac-

4 terisation of hotspots and deep mantle plumes. Recent full-waveform tomog5 raphy suggests that Earth's major plume conduits are vertical and broad, $6>600 \mathrm{~km}$ in diameter in the lower mantle, preferentially tilted in the upper 7 mantle and likely anchored at the base of the mantle French and Romanow- 
icz, 2015). The composition of olivine phenocrysts indicates upper mantle plume excess temperatures between $+150 \mathrm{~K}$ and +300 K (e.g. Putirka, 2005).

The vertical deflection of oceanic lithosphere by mantle plumes (e.g. Sleep, 1990; Crosby and McKenzie, 2009) and the propagation velocity of plumerelated V-shaped ridges (Poore et al., 2009, Parnell-Turner et al., 2014) con13 strain plume buoyancy fluxes to between $0.3 \times 10^{3} \mathrm{~kg} \mathrm{~s}^{-1}$ (Bowie, Sleep, 1990) and $>70 \times 10^{3} \mathrm{~kg} \mathrm{~s}^{-1}$ (Iceland, Parnell-Turner et al., 2014). Combining information on plume radius, excess temperature and buoyancy flux gives plume rising speeds between $23 \mathrm{~cm} \mathrm{yr}^{-1}$ and $54 \mathrm{~cm} \mathrm{yr}^{-1}$ (Poore et al., 2009: Turcotte and Schubert, 2014) and plume heat flow anomalies between 10-20 $\mathrm{mW} \mathrm{m}^{2}$ (Sleep, 1990).

Plumes can provide valuable information about the physics of mantle convection since they potentially interact with the whole mantle, including both the basal and top boundary layer. Several studies have focused on characterising the temporal stability of mantle plumes, because fixed plumes can serve as an absolute reference for global tectonic reconstructions (e.g. Wilson, 1963). However, paleomagnetic, geochronological and petrological studies suggest contrasting plume stability/mobility. Early geochronological and paleomagnetic observations (e.g. Morgan, 1981), and studies of the uncertainties of plate-reconstruction circuits (e.g. Duncan, 1981) suggested negligible Indo-Atlantic plume motions during the last $100 \mathrm{Myr}$. In contrast, more recent analyses of geochronological and paleomagnetic datasets suggested either a true polar wander episode (e.g. Koivisto et al. 2014), a change in Pacific plate motion (e.g. Torsvik et al., 2017), a southward motion of the Hawaiian plume reaching $4 \mathrm{~cm} \mathrm{yr}^{-1}$ between 81 and $47 \mathrm{Ma}$ (e.g. 
Tarduno et al., 2003), or a combination of plume and plate motion (e.g. Finlayson et al., 2018; Konrad et al., 2018) to explain the bent Hawaii-Emperor hotspot track. Petrological data also suggest that the Azores plume has drifted northwards by 1-2 $\mathrm{cm} \mathrm{yr}^{-1}$ along the Mid-Atlantic ridge over the last 85 Myr Arnould et al. 2019).

Numerical and laboratory experiments give independent constraints on mantle plume behaviour. The viscosity contrast between plume conduits and the ambient mantle (e.g. Jellinek and Manga, 2004)) may influence their dynamics and stability. Mantle convection has also been shown to contribute to plume motion. A highly viscous lower mantle (Richards, 1991) or the anchoring of plume conduits along the edges of dense basal thermochemical heterogeneities (e.g. Davaille et al., 2002) representing Large Low Shear Velocity Provinces (LLSVPs), is expected to stabilise plumes, while lateral mantle flow, sometimes called mantle wind (Duncan and Richards, 1991; Richards and Griffiths, 1988), would favour highly tilted plumes (Steinberger and O'Connell, 1998; O'Neill et al., 2005). Finally, plate tectonics have been proposed to promote plume stability via ridge capture (e.g. Tarduno et al. 2009). Subduction can also indirectly induce plume motions through the effect of supercontinent cycles on the planform of global convection (Zhong et al., 2007) or the lateral push of plume conduits by lower mantle slabs (Hassan et al. 2016).

Collectively, the above-mentioned studies highlight the need to investigate the coupled behaviour of mantle plumes, plate tectonics, large-scale mantle flow and basal thermochemical structures. Here we use time-dependent 3Dspherical numerical models of whole-mantle convection at Earth-like con- 
vective vigour and self-generating plate tectonics to jointly investigate the mechanisms linking plate tectonics, mantle convection and plume dynamics. In these models, drifting plumes arise self-consistently and dynamically interact with surface tectonics, large-scale and small-scale convection. Focusing on model plume conduits, we show that their number, lifetime, shape, temperature excess, rising speed, buoyancy and heat fluxes are comparable to observations. This serves as a basis to investigate the role of plate tectonics, plate layout, convective vigour of the lowermost mantle and basal thermochemical structures on plume spatio-temporal dynamics.

\section{Methods}

\subsection{Numerical models of mantle convection with plate-like tectonics}

We solve the equations of mass, momentum, energy and advection of compositional fields under the Boussinesq approximation to produce a series of 3D-spherical models of mantle convection with plate-like tectonics using the code StagYY (Tackley, 2008).

The reference Rayleigh number $\mathrm{Ra}_{0}$ used to model Earth-like mantle convective vigour is

$$
\mathrm{Ra}_{0}=\frac{\alpha_{0} \rho_{0} \mathrm{~g} \Delta \mathrm{TD}^{3}}{\kappa_{0} \eta_{0}}=10^{7}
$$

with $\alpha_{0}$ the surface thermal expansivity, $\rho_{0}$ the reference density, $g$ the gravitational acceleration, $\Delta T$ the temperature difference across the whole mantle domain, $D$ the mantle domain thickness, $\eta_{0}$ the reference viscosity and $\kappa_{0}$ the reference thermal diffusivity. All parameters are listed in Table 1 .

Viscosity varies both radially and laterally, and depends on both temper- 
ature and pressure as:

$$
\eta(T, z)=\eta_{0}(z) \exp \left(A+\frac{E_{a}+\Pi(z) V_{a}}{R T}\right)
$$

with $A$ chosen a priori so that $\eta=\eta_{0}$ when $T=0.64$ (dimensional equivalent $1,600 \mathrm{~K})$ at the lithosphere-asthenosphere boundary, $E_{a}$ the activation energy, $V_{a}$ the activation volume, $\Pi(z)$ the static pressure, $R$ the gas constant, $z$ the depth and $T$ the temperature. The activation energy and volume used in the models produce seven orders of magnitude of viscosity variation throughout the domain (Fig. S1). We impose a viscosity increase by a factor of 30 at $660 \mathrm{~km}$ depth, consistent with geoid and postglacial rebound studies Nakiboglu and Lambeck, 1980; Ricard et al., 1993). Although it remains debated (e.g. Rudolph et al., 2015), the chosen viscosity structure is comparable to most numerical studies (e.g. Steinberger and Calderwood, 2006). In order to achieve self-generation of a plate-like behaviour, we use a pseudo-plastic rheology in which viscosity depends on the yield stress (Tackley, 1998):

$$
\eta_{Y}=\frac{\sigma_{Y}}{2 \dot{\epsilon}_{\mathrm{II}}}
$$

with $\eta_{Y}$ the yielded viscosity, $\sigma_{Y}=\sigma_{Y_{0}}+z \times d \sigma_{Y}$ the yield stress where $\sigma_{Y_{0}}$ is the yield stress at the surface and $d \sigma_{Y}$ is its depth-dependence. $\dot{\epsilon}_{\mathrm{II}}=$ $\sqrt{0.5 \dot{\epsilon}_{i j} \dot{\epsilon}_{i j}}$ is the second invariant of the strain rate.

We consider five models to investigate the effect of mantle and subduction dynamics on mantle plumes characteristics and drift (Fig. 1, Table 2). In Model 1 (no yielding), we test the effect of a stagnant lid on plume stability. This model does not consider continents, contrary to Models 25. The surface yield stress of oceanic lithosphere is equal to $48 \mathrm{MPa}$ and to $27 \mathrm{MPa}$ in Models 2 and 3, respectively. These yield stress values are 
within the range of those determined from earthquake stress release Allmann and Schearer, 2009) and from rock mechanics experiments (e.g. Brace and Kohlstedt, 1980), although caution is required when comparing values inferred from mechanisms occurring at different spatial and temporal scales. They result in a mobile plate-like regime with slow (Model 3) or fast (Model 2) plate motions. In Models 1-3 thermal expansivity decreases with depth by a factor of three, to account for less vigorous convection in the lowermost mantle (Chopelas and Boehler, 1992). In Model 4 the surface yield stress is the same as in Model 2 but thermal expansivity is constant with depth, to test the effect of a more vigorous lowermost convection on plume drift. In Model 5, thermal expansivity varies with depth, the surface oceanic lithosphere yield stress is equal to $61 \mathrm{MPa}$ and an uppermost weak-crust layer of $14 \mathrm{~km}$ with a yield stress equal to $13 \mathrm{MPa}$ favours the formation of asymmetric subduction (Crameri et al., 2012). Model 5 is the last model of Coltice et al. (2019) for the period 555 to 905 Myr. It includes two basal chemical heterogeneities that are about 3\% denser and 10 times more viscous than the ambient mantle, initially $500 \mathrm{~km}$ thick and laterally homogeneous with a configuration comparable to present-day LLSVPs (see Fig. S3 of Coltice et al. (2019)). In Models 2-5, the yield-stress slightly increases with depth (Table 2). In Models 2, 3 and 4, the average radial resolution is $31 \mathrm{~km}$ while it is $23 \mathrm{~km}$ in Model 1 and 5; it is less than $15 \mathrm{~km}$ and $10 \mathrm{~km}$ near the surface and the core-mantle boundary respectively. The horizontal resolution at the surface varies between $26 \mathrm{~km}$ (Models 1 and 5) and $35 \mathrm{~km}$ (Model 2 - 4).

We track the evolution of compositional fields using the tracer-ratio method (Tackley and King, 2003). Model continents are low-density lithospheric 
rafts, thicker and stiffer than the oceanic lithosphere to prevent their entrainment by the convective flow (Table 1). Despite these characteristics, their margins are recycled through time (Supplementary Movies 1-3), consistent with estimates of continental recycling at subduction zones Coltice et al., 2019). Their initial shapes correspond to continents reconstructed either 80 Ma ago (separated, Models 2-4, Fig. S2c) or 200 Ma ago (aggregated, Model 5 Coltice et al. (2019)). In Models 1-4, after a preliminary equilibration phase of approximately 200 Myr during which tracers are not advected, we allow continents to dynamically interact within the convective environment for at least 200 Myr. We then analyse mantle plume behaviour over a subsequent period of approximately 350 Myr.

The use of pseudo-plasticity favours Earth-like surface velocities and tectonics (e.g. Coltice et al. 2017). As in Arnould et al. (2018), we verify that Models 2-5 favour plate-like behaviour with Earth-like plateness (proxy for the degree of surface deformation localisation, Tackley, 2000), surface mobility, plate velocities, heat flow and topography (Table 2, Fig. 1, Fig. S3(a), Movie S1 and S2).

\subsection{Automated detection of mantle plumes}

We developed a plume detection scheme to track plume positions and characteristics through time in map view. We located mantle plume conduits in the upper mantle (at 250, 350 and $670 \mathrm{~km}$ depth) and in the lower mantle (at 1,000 km depth) from their anomalously large radial heat advection, which is proportional to $v_{z} T$ (with $v_{z}$ the radial velocity and $T$ the temperature, Fig. S3b). Plumes were defined by upper and lower mantle heat advection equal to $190 \mathrm{~K} \mathrm{~m} \mathrm{yr}^{-1}$ (Fig. S4) and $48 \mathrm{~K} \mathrm{~m} \mathrm{yr}^{-1}$ respectively. 
The greater upper mantle threshold value reflects greater rising speeds. The use of the temperature (e.g. Labrosse, 2002) or radial velocity field alone (e.g. Hassan et al., 2015) is not selective enough to detect mantle plumes in our models. We chose a unique threshold at each depth to directly compare different models (Fig. S4). Results were verified visually for artifacts that could be introduced by the use of threshold values.

We used the connectivity method described in Labrosse (2002) in order to identify distinct plume conduits. We assigned identities (IDs) to plume conduits, and we inferred their location from their geometrical centroid. We tracked plumes in 1 Myr intervals by connecting plumes located within a radius of $500 \mathrm{~km}$ with a method similar to that of Hassan et al. (2015), although with a larger radius to follow plumes moving at several tens of

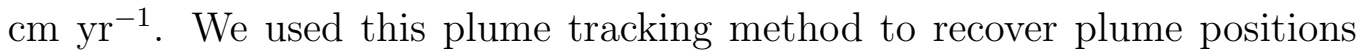
and characteristics in the upper and the lower mantle over time.

We used pyGPlates (Muller et al., 2018) to extract the time-dependent motion of each mantle plume conduit. We calculated absolute model plume velocities averaged over $5 \mathrm{Myr}$ to eliminate artificial plume wobbling caused by rapid readjustments of plume conduit shape. We calculated the relative motions of all plumes with respect to one another at $5 \mathrm{Myr}$ intervals to compare them to observations.

In StagYY, net rotation is zero at the surface. Therefore, in our models, "net rotation" is the net rotation of the mantle with respect to a fixed surface. 


\section{Phenomenology of model mantle plumes}

We first describe and quantify the spatio-temporal characteristics of model mantle plumes. The goal is to compare them to those deduced from observations to assess the applicability of our models to Earth.

\subsection{Number}

On average, we detected between 15 (Models 1 and 5) and 35 upper mantle plumes (Model 4) (Fig. 2a). The number of plumes remains relatively stable over the considered timescale. However, longer model evolutions suggest that supercontinent cycles influence the number of active plumes Coltice et al. 2019). The number of mantle plumes increases with plate-like behaviour (Models 2 and 3 versus Model 1) and with increasing core mantle boundary (CMB) heat flow. Indeed, the $15 \%$ larger CMB heat flow due to more vigorous lower mantle convection in Model 4 (Fig. 3f) leads to approximately $30 \%$ more plumes than in Model 2 (Fig. 2 a) while the presence of a basal thermochemical layer in Model 5 results in a CMB heat flow half that of Model 2 (Fig. 3f), and in a smaller number of plumes than in Model 2 (Fig. 2a).

The number of detected plumes is in broad agreement with other numerical models of whole-mantle convection although model parameters (including physical assumptions and surface boundary conditions) differ (e.g. Davies and Davies, 2009: Hassan et al., 2015; Li and Zhong, 2019). On Earth, the number of hotspots of lower mantle origin remains debated. Courtillot et al. (2003) used strict criteria to propose that only seven hotspots have a deep origin. Doubrovine et al. (2012) used only five deep mantle plumes to con- 
strain absolute plate motions. Wang et al. (2018) proposed 24 deep-rooted mantle plumes from criteria less strict than Courtillot et al. (2003).

\subsection{Lifetime}

In Models 2-4, 30\% of detected plumes exist for at least 200 Myr (Fig. 2b). In Model 1, all but one mantle plumes exist throughout the model evolution, suggesting that the absence of plate-like tectonics leads to longlived mantle plumes. In contrast, the lifetime of almost all plumes in Model 5 is shorter than 150 Myr (Fig. 2b), potentially because the deformation of basal thermochemical structures by slabs perturbs the buoyancy field that triggers and sustains mantle plumes (Heyn et al., 2018).

These results are compatible with the longest lived oceanic hotspot tracks for St-Helena (about 120 Myr), Tristan (about 120 Myr) and New England (about 130 Ma) plumes (Duncan, 1984; Williams et al., 2015). Shorterlived hotspot tracks (e.g. Hawaii and Louisville active at least from $87 \mathrm{Ma}$ ) terminate at subduction zones, but may have been active longer, the potential oldest parts of their tracks having been subducted (e.g. Portnyagin et al., 2008). Finally, geochemical analyses suggest that South Pacific Cook-Austral plumes have been active for at least $120 \mathrm{Ma}$ (e.g. Konter et al., 2008).

\subsection{Shape and radius}

In all models, large plume heads initiate in the lowermost mantle and reach the uppermost mantle (Movies S1 and S2). Most plumes consist of one individual conduit (Fig. 1). Some distinct upper mantle plume conduits are merged in the lower mantle (Fig. S8 and Movie S3). This is consistent with 
seismic tomography models that suggest a connection of Ascension and StHelena plumes below the transition zone (Montelli et al., 2006), of the Azores, the Canaries and Cape-Verde below 1,400 km depth and of Kerguelen and Crozet below 2,300 km depth (Davaille and Vatteville, 2005).

We quantified mantle plume tilt angle to investigate the possible effect of lateral mantle flow on their motions (Richards and Griffiths, 1988). Model plume conduits are generally vertical: the average tilt angle between 1,000 km depth and $350 \mathrm{~km}$ depth is approximately $5.5^{\circ}$ in Models 1-4 (Fig. 4a) and $16.5^{\circ}$ in Model 5 . In all models, only a limited proportion of plume conduits is deflected by more than $10^{\circ}$; tilt angles rarely reach the $60^{\circ}$ maximum used in plume-particle backward advection models (e.g. Steinberger and O'Connell, 2000). Mantle plume conduits are more likely deflected in the upper mantle than in the lower mantle, consistently with seismic tomography French and Romanowicz, 2015): in Model 2, the upper-mantle average tilt angle is equal to $15^{\circ}$, compared to $28^{\circ}$ in Model 5 (Fig. $4 \mathrm{~b}$ ), due to upper mantle shearing by surface plates, which can also cause deformation of the thermal trail of plumes (Fig. $4 \mathrm{~b}$ ).

The average upper mantle plume radius varies from $130 \mathrm{~km}$ for stagnantlid convection (Model 1) to $75 \mathrm{~km}$ for vigorous lower mantle convection (Model 4). Buoyancy fluxes deduced from hotspot topographic swells (Sleep, 1990) indicate that the average radius of upper mantle plume conduits is of the order of $100 \mathrm{~km}$. This radius is small compared to seismic tomography resolution, which explains the difficulties in imaging plume conduits.

The radius of plume conduits is systematically greater in the lower mantle than in the upper mantle $(377 \mathrm{~km}$ in Model 1 at 1,000 km depth to $131 \mathrm{~km}$ 
in Model 4, Fig. 1 and S6a). The difference in plume conduit radius between the lower and upper mantle is due to the 30 fold viscosity jump imposed at $670 \mathrm{~km}$ depth (e.g. Leng and Gurnis, 2012). The presence of thermochemical heterogeneities within plumes (Davaille and Vatteville, 2005) and the visco-plastic rheology of the lower mantle (Davaille et al., 2018) might partly explain why lower mantle plumes are broader in tomography models (French and Romanowicz, 2015).

In Model 5, all plumes but one are anchored to basal thermochemical heterogeneities (about 120 different hotspots were detected over $350 \mathrm{Myr}$ ). Plumes originate from topographic crests (Fig. 1), either along the edges or on the top of the basal thermochemical heterogeneities, as in previous models that consider dense and hot basal material (Garnero and McNamara, 2008; Hassan et al., 2015; Li and Zhong, 2017, 2019).

\subsection{Excess temperature}

Model plume average excess temperature is defined as the difference between the average temperature over their cross-sectional area and the average mantle temperature at $350 \mathrm{~km}$ depth. The average excess temperature of model plume conduits over their cross-sectional area is + $140 \mathrm{~K}$ in Model 1 and $+200-225 \mathrm{~K}$ in Models 2-5 (Fig. 3b), which is consistent with petrological studies (e.g. Putirka, 2005). The lower excess temperature in Model 1 results from the stagnant-lid regime leading to a larger ambient mantle temperature in this model. The average excess temperature decreases with depth along plume conduits (Fig. S6b): it is for example $450 \mathrm{~K}$ in average for Model 2 at $1000 \mathrm{~km}$ depth. 


\subsection{Buoyant rising speed}

In Models 1-4 (thermal plumes only), plume material rises in the upper mantle at approximately $30 \mathrm{~cm} \mathrm{yr}^{-1}$ on average (Fig. 3c).

The average rising speed is consistent with the modified Stokes velocity (Richards and Griffiths, 1988):

$$
v_{p}=\frac{k_{p} \Delta \rho g r_{p}^{2}}{\eta} \approx 24 \mathrm{~cm} \mathrm{yr}^{-1}
$$

with $\eta \approx 110^{20} \mathrm{~Pa}$ s the viscosity of the upper mantle in our models (Fig. S1), $k_{p} \approx 0.54$ a geometrical constant determined experimentally, $\Delta \rho=$ $\alpha \rho_{m} \Delta T \approx 22 \mathrm{~kg} \mathrm{~m}^{-3}$ the density contrast between thermal plumes and the surrounding upper mantle (where $\Delta T \approx 200 \mathrm{~K}, \alpha$ is the thermal expansivity and $\rho_{m}$ is the reference density), $g$ the gravitational acceleration and $r_{p} \approx$ $80 \mathrm{~km}$ the plume radius.

In Model 5 (thermochemical plumes), buoyant rising upper mantle speeds are only approximately $17 \mathrm{~cm} \mathrm{yr}^{-1}$ because entrained denser basal material decreases the positive thermal buoyancy of plume material.

\subsection{Buoyancy flux}

We calculated the buoyancy flux of mantle plumes as in Sleep (1990) (Fig. 3d):

$$
B_{p}=\rho_{m} \alpha \Delta T A_{p} v_{p}
$$

with $\rho_{m}$ the reference mantle density, $\alpha$ the reference thermal expansivity, $\Delta T$ the mantle plume temperature excess, $A_{p}$ the cross-sectional area of mantle plume conduits and $v_{p}$ the buoyant rising speed. In Models 2-4, plume buoyancy flux ranges between 0.01 and $20 \times 10^{3} \mathrm{~kg} \mathrm{~s}^{-1}$ and is $\sim 5 \times 10^{3} \mathrm{~kg} \mathrm{~s}^{-1}$ 
on average. In Model 1 , it is $8 \times 10^{3} \mathrm{~kg} \mathrm{~s}^{-1}$ on average because of the larger cross-sectional area of mantle plumes, and in Model 5 it is $2.5 \times 10^{3} \mathrm{~kg} \mathrm{~s}^{-1}$ because of the lower plume rising speed. This range of model plume buoyancy fluxes is comparable to estimates for present-day hotspots (Crosby and McKenzie, 2009).

\subsection{Heat flow}

Plume heat flow was derived from the buoyancy flux as in Sleep (1990):

$$
F_{p}=B_{p} \frac{c_{p}}{\alpha}
$$

where $c_{p}$ is the mantle heat capacity in $\mathrm{J} \mathrm{kg}^{-1} \mathrm{~K}^{-1}$. Individual plumes advect about $0.08-0.23 \mathrm{TW}$ of heat on average in Models 1-5 (Fig. 3e). In Models 1-5, the core heat flow varies between 3 TW (Models 5) and 6.3 TW (Model 4, Fig. 3f), and never exceeds $20 \%$ of the surface heat flow (Fig. S5), which is at the lowest end of observational constraints (5-15 TW, Lay et al., 2008). The amount of heat carried by mantle plumes at $350 \mathrm{~km}$ depth represents $\sim 3 \mathrm{TW}$ in Models 1-4 and $\sim 1.5 \mathrm{TW}$ in Model 5, about $2 \mathrm{TW}$ less than the corresponding heat flow (Fig. 3f). Davies (1988) and Sleep (1990) estimated the contribution of plumes to the total surface heat flow as 2.5 TW from hotspot swells. At $350 \mathrm{~km}$ depth, model mantle plumes carry a similar amount of heat. The ratio of upper-mantle plume heat flow to core heat flow (about 50-60\% in Models 1-5) is consistent with numerical models of incompressible and isoviscous (Labrosse, 2002) or temperature-dependent viscosity convection with different internal heating rates Mittelstaedt and Tackley, 2006). 
The amount of heat carried by each plume is about 1.5 times larger at $1000 \mathrm{~km}$ depth than at $350 \mathrm{~km}$ depth (Fig. S6). Mittelstaedt and Tackley (2006) showed that plumes contribute to heat up sinking slabs, therefore losing some heat on their way up (Fig. S6). Using extended-Boussinesq (Leng and Zhong, 2008: Zhong, 2006) and compressible models (Bunge, 2005), it was also suggested that the proportion of core heat flux advected by plumes decreases towards the surface following a steep plume adiabatic gradient.

\subsection{Pulses of activity}

The activity of a given mantle plume progressively decreases through time, as evident in the decrease of plume maximum temperature excess from $+500 \mathrm{~K}$ to $+200 \mathrm{~K}$ for a hotspot in Model 2 (Fig. 2d). This temperature decrease is consistent with geological estimates of the temperature evolution of the Galapagos and Iceland plumes (Herzberg and Gazel, 2009). The long-term decrease of the activity of a plume is punctuated by shorter-term fluctuations in flux by about $\pm 1 \times 10^{3} \mathrm{~kg} \mathrm{~s}^{-1}$ on 5 -10 Myr timescales. Changes in plume buoyancy flux tend to occur after plume merging events or after interaction with a ridge (Fig. 2d).

\subsection{Absolute motions of plumes}

In Model 1 (stagnant lid), the average absolute drift of plumes in the upper mantle is $0.6 \mathrm{~cm} \mathrm{yr}^{-1}$. In contrast, the average absolute lateral speed of upper mantle plumes is approximately $1.8 \mathrm{~cm} \mathrm{yr}^{-1}$ in Models 2 and 3, $2.2 \mathrm{~cm} \mathrm{yr}^{-1}$ in Model 4 (more vigorous lower mantle convection), and $2.4 \mathrm{~cm} \mathrm{yr}^{-1}$ in Model 5 (deep thermochemical piles), which is characterised by more slowly rising plumes (Table 2). Average absolute lateral speeds of 
plume conduits in the lower mantle are 15 to $40 \%$ lower than in the upper mantle, depending on model parameters; they vary between $0.4 \mathrm{~cm} \mathrm{yr}^{-1}$ (Model 1) and $2 \mathrm{~cm} \mathrm{yr}^{-1}$ (Model 5). This reflects that some plumes are tilted by vigorous upper mantle convection.

\subsection{Relative motion between plumes}

We quantified the evolution of the relative motion of pairs of plumes (Table 2 and Fig. 5) to study the processes controlling plume lateral motion. This allowed us to statistically compare the lateral motions of model plumes with observations without considering the global reference frame of tectonic reconstructions. The average relative speed between mantle plumes in the upper mantle is $0.6 \mathrm{~cm} \mathrm{yr}^{-1}$ in Model $1,1.6 \mathrm{~cm} \mathrm{yr}^{-1}$ in Models 2 and 3, and $2.2 \mathrm{~cm} \mathrm{yr}^{-1}$ in Models 4 and 5. Relative velocities between mantle plumes are systematically lower than the average absolute motion of plumes in models with a plate-like tectonic behaviour, which suggests a coherent drift of at least some mantle plumes (see section 4.2). However, in these models, the net motion of the mantle relative to the surface has a small effect on plume lateral motion because it is only about 0.03-0.04 ${ }^{\circ} \mathrm{Myr}^{-1}$ (Table 2), at the low end of net rotation estimates (Tetley et al., 2019).

More than $76 \%$ of model plumes move by less than $2 \mathrm{~cm} \mathrm{yr}^{-1}$ depending on model parameters (Fig. 5a). This is comparable to results from Li and Zhong (2019), after the removal of the net motion of the mantle from their modeled plume motions; in their models, large mantle net rotation results from both imposed surface boundary conditions containing net-rotation up to $0.55^{\circ} \mathrm{Myr}^{-1}$, and stronger viscous coupling between the lithosphere and asthenosphere. 
Doubrovine et al. (2012) produced a global moving hotspot reference frame from the best fit of advected tracers within a reconstructed mantle flow during the last 130 Ma with the tracks of 44 well-known hotspots. They found that limited plume motion (drift of less than $3 \mathrm{~cm} \mathrm{yr}^{-1}$ for any plume, Fig. 5a) and large plume deflection could explain observed hotspot tracks. This scenario requires plumes to drift slower than in Models 2-5. However, this reference frame results in large lithospheric net rotation (Table 2), and it neglects potential large uncertainties on both hotspot track ages and paleo-locations, as well as uncertainties in backward-advection mantle flow models. To overcome the limitations associated with the use of uncertain paleomagnetic estimates and incomplete geological record, Tetley et al. (2019) generated an absolute plate motion model assuming fixed hotspots and optimising trench motion, lithospheric net rotation and hotspot track geometry. From the difference between nine modeled and observed hotspot tracks, they estimated relative mantle plume motions as $2.07 \pm 0.8 \mathrm{~cm} / \mathrm{yr}$, which is $85 \%$ larger than Doubrovine et al. (2012). Our results are compatible with that of Tetley et al. (2019) (Fig. 5 a and Table 2).

\subsection{Topographic swell}

In all models, the buoyancy force of mantle plumes leads to the formation of a surface topographic swell 1000-2000 km across and 1-2 km high (Fig. 1. S3 and S5). The swell extent and amplitude depend on 1/ plume buoyancy flux that decreases over time (Fig. 2 and Movies S1 and S2), 2/ the nature of the impacted lithosphere (thickness, type, plate boundary proximity) and $3 /$ the relative motion between the plume and the lithosphere, which can shear the conduit and result in an asymmetric shape of the plume trail (Fig. S2, 
Movies S1 and S2; see also Arnould et al. 2019).

\subsection{Plume-ridge interactions}

In Models 2-4, 30 to $50 \%$ of mantle plumes interact with ridges at one point. This proportion increases to $45-80 \%$ for Model 5 in which the weaker lithosphere is more likely to break above mantle plumes. The increasing number of plumes interacting with ridges during the last 150 Myr in Model 5 represents a rise of total ridge length during a significant rifting event, with the newly formed ridges connecting over preexisting mantle plumes Coltice et al. 2019). This preferential relation between ridges and mantle plumes was first noted by Wilson (1965).

Some model plumes interacting with ridges are relatively stable $\left(<2 \mathrm{~cm} \mathrm{yr}^{-1}\right)$ and stay in the vicinity of a long-lived ridge for at least $50 \mathrm{Myr}$ (Fig. 6a). This case represents the proposed long-term interactions between the MidAtlantic ridge and Tristan, St-Helena and the Azores (e.g. Gente et al., 2003). Plumes moving along or near a ridge can favour ridge-jumps (Fig. 6b), in a configuration comparable to the interaction of the Nazca ridge with the Galapagos hotspot (Wilson and Hey, 1995). Such jumps can also occur when a plume reaches the surface in the vicinity of an existing ridge, resulting in the relocation of the ridge axis above the newly-formed hotspot. This phenomenon has been invoked for the formation of the Elan bank during the emplacement of the Kerguelen plateau and in the Tasman Sea Gaina et al. 2003), although paleomagnetic measurements in these regions are debated (Sandwell and Smith, 1997). This mechanism possibly explains why slowly-migrating ridges often interact with plumes (Whittaker et al., 2015). Finally, some plumes can cross ridge axes and contribute to the propagation 
of a new spreading axis (Fig. 6c). This case shares similarities with the Réunion hotspot crossing the Central Indian Ridge about 30 Myr ago and its putative link to the formation of the Rodriguez ridge (Morgan, 1978).

\section{Sources of plume drift}

We used the above analysis of the characteristics of model plumes to classify the lateral plume motions into categories. We used Model 1 as a reference to define four categories reflecting four different processes.

\section{1. "Fixed" plumes}

In Model 1, $60 \%$ of plumes move by less than $0.5 \mathrm{~cm} \mathrm{yr}^{-1}$ relatively to each other (Fig. 5a). These plumes are rooted at saddle points of basal flow and therefore remain stable throughout their lifetime. This stability is favoured by the absence of plate tectonics at the surface, since the number of fixed plumes decreases to between 25\% (Model 5) and 50\% (Model 3) when platelike behaviour occurs (Fig. 5a). The most stable plumes are still located at saddle points of lowermost mantle flow (such as Plume IDs 1, 4, 7, 16 and 21 on Fig. S9), which is consistent with the numerical models of Zhong et al. (2000). In Li and Zhong (2019), the proportion of fixed plumes is 10-20\%, possibly due to the deep mantle rotation rotation induced by imposed plate velocities (Rudolph and Zhong, 2014).

\subsection{Basal mantle flow entrainment}

In Model 1, about 30\% of model plumes move at relative speeds comprised between 0.5 and $1 \mathrm{~cm} \mathrm{yr}^{-1}$ (Fig. 5a). Such lateral speeds are consistent with average lower mantle lateral motions (Table 2), suggesting entrainment of 
these plumes by lateral flow in the lowermost mantle. In Models 2-5, the number of slowly-moving plumes varies from $25 \%$ of the total number of plumes (Model 4) to 40\% (Model 2). The lateral motion of such plumes (e.g. IDs 18 and 18) coincides in direction and magnitude with lowermost mantle flow in their vicinity (Fig. 5 a and Table 2 ).

\subsection{Slab-induced drift}

This category of plumes drifting at speeds between $1-5 \mathrm{~cm} \mathrm{yr}^{-1}$ over several tens of million years only occurs with plate-like behaviour (Models 2-5) and is indirectly related to subduction dynamics. 28\% (Model 2) to $40 \%$ (Model 5) of model plumes belong to this category (Fig. 5). In these models, slabs penetrating in the lower mantle as far as 5,000 km away from mantle plumes modify the mantle pressure field by generating regional positive pressure gradients in the basal thermal boundary layer (Fig. 7a) resulting in plume motions at about $2 \mathrm{~cm} \mathrm{yr}^{-1}$. Some close conduits can therefore be pushed in a similar directions by these regional reorganisations of mantle flow, such as Plume ID 6, 10 and 15 in Model 2 (Fig. S9). Faster lateral motions result from complex interactions between plume conduits (which are subsequently highly deformed) and slabs in the upper mantle and the uppermost lower mantle (Movies S1, S2 and S3). In Model 5, slabs also contribute to deforming the edges of thermochemical heterogeneities and therefore indirectly push mantle plumes. This process is consistent with the scenario proposed by Hassan et al. (2016) to explain the fast $\left(>4 \mathrm{~cm} \mathrm{yr}^{-1}\right)$ drift of the Hawaii plume between 81 and 47 Ma. 


\subsection{Rapid drift due to plume merging events}

Independent of the presence of surface plate-like motions, all models feature plumes with lateral speeds exceeding $5 \mathrm{~cm} \mathrm{yr}^{-1}$ and reaching $10 \mathrm{~cm} \mathrm{yr}^{-1}$ (Model 1) to $22 \mathrm{~cm} \mathrm{yr}^{-1}$ (Models 2 and 4). Less than $5 \%$ of all mantle plumes drift at such speeds which occur when two mantle plumes, whose roots are within a few hundreds of kilometres of one another, merge (Fig. 7b). Plume merging events have a recurrence time varying between 35 Myr (Models 3 and 5) and $200 \mathrm{Myr}$ (Models 1 and 2). Merging between two mantle plumes always starts at the base of the mantle due to a basal pressure difference between two close conduits, and propagates to the upper mantle, where the last merging steps occur over less than 10 Myr (Fig. 5b and Fig. 7b). Merging between two mantle plumes has been described in mantle convection models (Davies and Davies, 2009), but fast lateral motions of merging mantle plumes have not yet been documented on Earth, which could be explained by the rare occurrence and short duration of such model events.

\section{Discussion}

\subsection{Limitations of models and analysis}

We tested a limited number of parameters potentially affecting plume drift. For example, we only considered one parameterisation (initial thickness, density and viscosity contrasts) to model basal thermochemical heterogeneities, although the nature of LLSVPs remains debated (e.g. Garnero et al., 2016). Moreover, although the resolution at $350 \mathrm{~km}$ depth in Models $2-4(33 \mathrm{~km})$ is lower than the one of Models 1 and $5(24 \mathrm{~km}$, similar to the lateral resolution of $\mathrm{Li}$ and Zhong $(2019)$ ), the range of the detected 
cross-sectional areas for all models are consistent (Fig. 3a). Furthermore, we achieved radial and lateral viscosity contrasts as large as $10^{7} \mathrm{~Pa}$ s at the expense of model computational time: each model required about 145,000 CPU hours over three months of calculation on a parallel supercomputer to model mantle flow over 350 Myr.

Our plume detection algorithm is based on the hypothesis that all mantle plumes are characterised by significant heat advection, and therefore by both substantial temperatures and large rising speeds. This method makes it possible to characterise model plume dynamics, however results depend on $1 /$ the ability to detect a potentially large variety of plumes in models with distinct parameters, and $2 /$ on the threshold that is set for plume detection. This threshold was defined by comparing the number of plumes detected by the algorithm to the number of mantle plumes detected visually.

\subsection{What controls plume dynamics?}

Here, we focus on the causes of lateral motions of already developed plumes and do not investigate the controls on the position of their source, „which is likely to also affect their dynamics (e.g. Heyn et al., 2018; Li and Zhong, 2017).

\subsubsection{Indirect control by plate tectonics}

Despite these limitations, we show that planetary surface dynamics exerts a first-order control on plume drift: if the surface is in stagnant lid, stable or slowly moving plumes predominate. The impossibility for mantle plumes to drift rapidly in the absence of plate tectonics and lithospheric thickness heterogeneities was noted by Zhong (2009) who studied the origin of Martian 
volcanism. Plate-like behaviour promotes faster plume motion (Fig. 5) due to the interaction of plume conduits with slabs in the upper or the lower mantle. Nevertheless, we see no significant effect of the number of plates (comparison between Model 2 and 3) on the statistical distribution of lateral plume motions.

\subsubsection{Limited stabilisation of mantle plumes by mid-ocean ridges}

It has been proposed that mantle plumes can be pinned to stable ridges (Tarduno et al., 2009). In our models, three plume behaviours arise depending on the type of spreading centre they interact with. A limited number of plumes pond below and remain fixed to long and stable ridges (e.g. Hotspot 7 in Fig. S9, from $90 \mathrm{Ma}$ ), consistently with Whittaker et al. (2015). In contrast, plumes may move along a stable ridge due to slab-induced lower mantle flow during several tens of million years (Hotspots 10 and 15 of Fig. S9). The possible slow motion of the Azores plume could fall in that category Arnould et al., 2019). Finally, mantle plumes interacting with fast-migrating ridges, usually neighbouring small plates affected by fast reorganisations, tend to move laterally faster and more eratically (Fig. 6d). We find no statistical difference in the lateral motion distribution of plumes as a function of their interacting with ridges (Fig. 8a).

\subsubsection{The role of the mantle environment on plume dynamics}

Lower mantle convection vigour seems to play a limited role in plume drift (comparison between Model 2 and 4) while affecting the number of active plumes. This result is consistent with that of Li and Zhong (2019), who did not detect any change in the statistical distribution of plume lateral 
motions when changing the Rayleigh number in mantle convection models with imposed plate histories.

We do not observe significant and systematic plume conduit deflection by mantle wind (Fig. 4). The strong temperature-dependence of mantle viscosity causes plume material to rise 10-100 times faster than typical ambient flow in the upper mantle (Fig. 35). Therefore, plume material rises too quickly to be substantially deflected (Fig. 4b). This conclusion differs from the results of numerical models of mantle convection with imposed plate history (e.g. Steinberger and O'Connell, 1998; O'Neill et al., 2005), which advocate for a strong effect of mantle wind on plume conduit tilting and plume motions to fit hotspot tracks. However, these models do not consider fully-dynamic mantle plumes. Instead, passive tracers are advected within a seismically and tectonically reconstructed mantle flow at a constant rising speed $\left(2.2 \mathrm{~cm} \mathrm{yr}^{-1}\right.$ in Steinberger and O'Connell (1998) to $10 \mathrm{~cm} \mathrm{yr}^{-1}$ in Steinberger and Antret$\operatorname{ter}(2006)$ ) and with an assigned maximal tilt angle of $60^{\circ}$, constrained by experimental values on chemical plumes (Whitehead, 1982). We note that our model plumes generate Earth-like buoyancy fluxes, that our findings are consistent with other numerical studies of mantle convection with a free-slip surface (Zhong et al., 2000; Davies and Davies, 2009) and that models with imposed plate history also generate mainly vertical fully-dynamic plumes $(\mathrm{Li}$ and Zhong, 2019) as opposed to significantly deflected plumes.

Model mantle plumes rooted at the edges of basal thermochemical heterogeneities tend to be more mobile (Fig. 5a) and are more likely to be deflected (Fig. 4) than purely thermal plumes (Davaille et al., 2002; Li and Zhong, 2019) because the entrainment of dense material by plume conduits 
slows their rise by a factor of two in our experiments.

\subsubsection{Plume characteristics are not diagnostic of plume motions}

We assess the relationships between model plume lateral velocities and age (defined as the time since a new plume was first detected), tilt angle, temperature excess, rising speed and buoyancy flux, to explore whether it may be possible to estimate plume drifting rates from such observations for Earth (Fig. 8 and S10). We find that plume age, temperature excess, rising speed and buoyancy flux do not correlate with absolute plume velocity. Moreover, plume tilt angles do not correlate with plume drifting rates (Fig. 8b). Instead, fast-moving plumes are characterized by small tilt angles. This suggests that intrinsic plume characteristics cannot be used as a diagnostic for plume drift.

\subsection{Implications for absolute plate reconstructions}

The study of the statistical behaviour of mantle plumes is critical to interpret the paleomagnetic and geochronological record and to build absolute plate reference frames based on moving hotspots for the last $\sim 80 \mathrm{Myr}$. In our study, 25\% (Model 5) to 50\% (Model 3) of plumes move at $<0.5 \mathrm{~cm} \mathrm{yr}^{-1}$ during several tens of millions of years in models with plate tectonics. This significant proportion of slow-moving plumes is comparable to the proportion of stable hotspots of Doubrovine et al. (2012) and Tetley et al. (2019), in which $52 \%$ and $30 \%$ of Earth plumes move by less than $0.5 \mathrm{~cm} \mathrm{yr}^{-1}$, respectively (Fig. 5a), although we note that observations of plume absolute motions are uncertain, notably for motion along the direction of hotspot tracks (Li and Zhong, 2019). We can nevertheless propose that such hotspots 
can be used as a robust non-moving reference to reconstruct plate motions.

Moreover, our results show that plumes with different drifting rates can coexist within the same global convective system, depending on their location and potential interactions with slabs, plate tectonics and regional convective flow (Fig. S9). Indeed, model plume velocities can exceed $2 \mathrm{~cm} \mathrm{yr}^{-1}$, consistent with geochronological and paleomagnetic observations for Hawaii (Tarduno et al., 2003; Konrad et al., 2018) and Kerguelen (Antretter et al. 2002). Our study therefore reconciles contradictory observations of plume drift and suggests that defining a global reference frame based on hotspot tracks to reconstruct past absolute plate motions requires the careful selection of slow-moving plumes based on paleomagnetic and geochronological data.

\section{Conclusion}

We presented mantle plumes arising in models of mantle convection selfgenerating plate-like tectonics that display excess temperatures, rising speed and buoyancy fluxes comparable with Earth's major hotspots. In the absence of plate tectonics, mantle plumes are long-lived, vertical and fixed. In models with plate tectonics, plumes rise vertically with deflection $<10^{\circ}$ on average, usually limited to the more vigorously convecting upper mantle, consistently with recent tomographic models (French and Romanowicz, 2015). Plume lifetime is shorter with tectonics than in stagnant lid mode, with half of plumes existing for less than $50 \mathrm{Myr}$, although some plumes may exist for hundreds of million years. The coexistence of several long-lived plumes with short-lived ones is consistent with observations from LIPs (Large Igneous 
Provinces) and hotspot tracks.

With plate tectonics, plumes are in general mobile. We identified four distinct groups of plumes:

1. 25-50\% of plumes are fixed to saddle points of the basal mantle flow.

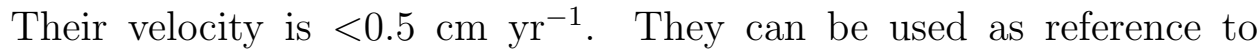
reconstruct absolute plate motions.

2. 25 to $40 \%$ of plumes are entrained by passive mantle flow; they move

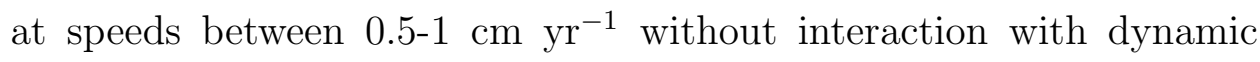
instabilities such as slabs or other plumes.

3. 30-40\% of plumes are pushed by slabs sinking in the lowermost mantle that generate high pressures in the basal boundary layer, pushing plumes towards lower pressure regions. Such plume motion is between 1 and $5 \mathrm{~cm} \mathrm{yr}^{-1}$, can last several tens of million years, and may explain the large speeds of the Hawaiian plume (e.g. Konrad et al., 2018).

4. Rare (once every $200 \mathrm{Myr}$ in some models) merging of close plumes due to a pressure difference in the basal boundary layer. Merging starts in the thermal boundary layer at a slow pace. Plumes drift at speeds > $5 \mathrm{~cm} \mathrm{yr}^{-1}$ over less than 10 Myr once merging propagates to the upper mantle.

The limited deflection of plume conduits results from their strong temperature dependence of viscosity. The entrainment of basal thermochemical material by mantle plumes decreases their buoyant rising speed, leading to enhanced plume deflection, lateral plume motion and shorter lifetime.

Our models suggest that ridges are passive enough to interact with plumes but not to systematically influence the flow where plumes originate. Some 
plumes leave ridge segments, other move along with a fast-drifting ridge, and some move along a stable ridge axis.

The intrinsic properties of plumes observed from the surface (age, excess temperature, buoyancy flux, rising speed, tilt angle) are not diagnostic of plume motion since they do not correlate with lateral plume velocity.

\section{Acknowledgements}

The research leading to these results received funding from the European Research Council within the framework of the SP2-Ideas Program ERC-2013CoG, under ERC grant agreement 617588. N. F. was supported by ARC grants DE160101020 and LP170100863 and C. M. was supported by ARC grant IH130200012. This research benefited from the assistance of resources from the National Computational Infrastructure (NCI), which is supported by the Australian Government. We thank S. Zhong and K. Konrad for their constructive reviews that improved this article.

\section{References}

Allmann, B.P., Schearer, P.M., 2009. Global variations of stress drop for moderate to large earthquakes. Journal of Geophysical Research 114.

Antretter, M., Steinberger, B., Heider, F., Soffel, H., 2002. Paleolatitudes of the kerguelen hotspot: new paleomagnetic results and dynamic modeling. Earth and Planetary Science Letters 202, 635-650.

Arnould, M., Coltice, N., Flament, N., Seigneur, V., Muller, R.D., 2018. On the scales of dynamic topography in whole-mantle convection models. Geochemistry, Geophysics, Geosystems 19, 3140-3163. 
Arnould, M., Ganne, J., N., C., Feng, X., 2019. Northward drift of the azores plume in the earth's mantle. Nature Communications 10.

Brace, W., Kohlstedt, D., 1980. Limits on lithospheric stress imposed by laboratory experiments. Journal of Geophysical Research 85, 6248-6252.

Bunge, H.P., 2005. Low plume excess temperature and high core heat flux inferred from non-adiabatic geotherms in internally heated mantle circulation models. Physics of the Earth and Planetary Interiors 153, 3-10.

Chopelas, A., Boehler, R., 1992. Thermal expansivity in the lower mantle. Geophysical Research Letters 19, 1983-1986. doi:10.1029/92GL02144.

Coltice, N., Gerault, M., Ulvrova, M., 2017. A mantle convection perspective on global tectonics. Earth Science Reviews 165, 120-150.

Coltice, N., Husson, L., Faccenna, C., Arnould, M., 2019. What drives tectonic plates? Science Advances 5 .

Courtillot, V., Davaille, A., Besse, J., Stock, J., 2003. Three distinct types of hotspots in the earth's mantle. Earth and Planetary Science Letters 205, 295-308.

Crameri, F., Tackley, P., Meilick, I., Gerya, T., Kaus, B., 2012. A free plate surface and weak oceanic crust produce single-sided subduction on earth. Geophysical Research Letters 39. doi:10.1029/2011GL050046.

Crosby, A., McKenzie, D., 2009. An analysis of young ocean depth, gravity and global residual topography. Geophysical Journal International 178, 1198-1219. 
Davaille, A., Carrez, P., Cordier, P., 2018. Fat plumes may reflect the complex rheology of the lower mantle. Geophysical Research Letters 45, 13491354 .

Davaille, A., Girard, F., Le Bars, M., 2002. How to anchor hotspots in a convecting mantle? Earth and Planetary Science Letters 203, 621-634.

Davaille, A., Vatteville, J., 2005. On the transient nature of mantle plumes. Geophysical Research Letters 32.

Davies, D.R., Davies, J.H., 2009. Thermally-driven mantle plumes reconcile multiple hot-spot observations. Earth and Planetary Science Letters 278, $50-54$.

Davies, G.F., 1988. Ocean bathymetry and mantle convection: 1. largescale flow and hotspots. Journal of Geophysical Research: Solid Earth 93, $10467-10480$.

Doubrovine, P.V., Steinberger, B., Torsvik, T.H., 2012. Absolute plate motions in a reference frame defined by moving hot spots in the pacific, atlantic, and indian oceans. Journal of Geophysical Research: Solid Earth 117.

Duncan, R., 1981. Hotspots in the southern oceans - an absolute frame of reference for motion of the gondwana continents. Tectonophysics 74, 29-42.

Duncan, R., 1984. Age progressive volcanism in the new england seamounts and the opening of the central atlantic ocean. Journal of Geophysical Research 89, 9980-9990. 
Duncan, R.A., Richards, M.A., 1991. Hotspots, mantle plumes, flood basalts, and true polar wander. Reviews of Geophysics 29, 31-50.

Finlayson, V., Konter, J., Konrad, K., Koppers, A., Jackson, M., Rooney, T., 2018. Sr-pb-nd-hf isotopes and 40ar/39ar ages reveal a hawaii-emperorstyle bend in the rurutu hotspot. Earth and Planetary Science Letters 500, 168-179.

French, S.W., Romanowicz, B., 2015. Broad plumes rooted at the base of the earth's mantle beneath major hotspots. Nature 525, 95.

Gaina, C., Muller, R., Brown, B., Ishihara, T., 2003. Microcontinent formation around australia. Special papers - geological society of America, 405-416.

Garnero, E.J., McNamara, A.K., 2008. Structure and dynamics of earth's lower mantle. Science 320, 626-628.

Garnero, E.J., McNamara, A.K., Shim, S.H., 2016. Continent-sized anomalous zones with low seismic velocity at the base of earth's mantle. Nature Geoscience 9, 481.

Gente, M., Dyment, J., Marcia, M., Goslin, J., 2003. Interaction between the mid-atlantic ridge and the azores hot spot during the last 85 myr: Emplacement and rifting of the hot spot-derived plateaus. Geochemistry, Geophysics, Geosystems 4.

Hassan, R., Flament, N., Gurnis, M., Bower, D.J., Müller, D., 2015. Provenance of plumes in global convection models. Geochemistry, Geophysics, Geosystems 16, 1465-1489. 
Hassan, R., Müller, R.D., Gurnis, M., Williams, S.E., Flament, N., 2016. A rapid burst in hotspot motion through the interaction of tectonics and deep mantle flow. Nature 533, 239-242.

Herzberg, C., Gazel, E., 2009. Petrological evidence for secular cooling in mantle plumes. Nature 458, 619.

Heyn, B.H., Conrad, C.P., Tronnes, R.G., 2018. Stabilizing effect of compositional viscosity contrasts on thermochemical piles. Geophysical Research Letters 45, 7523-7532.

Jellinek, A.M., Manga, M., 2004. Links between long-lived hot spots, mantle plumes, d, and plate tectonics. Reviews of Geophysics 42 .

Koivisto, E.A., Andrews, D.L., Gordon, R.G., 2014. Tests of fixity of the indo-atlantic hot spots relative to pacific hot spots. Journal of Geophysical Research: Solid Earth 119, 661-675.

Konrad, K., Koppers, A.A., Steinberger, B., Finlayson, V.A., Konter, J.G., Jackson, M.G., 2018. On the relative motions of long-lived pacific mantle plumes. Nature communications 9, 854 .

Konter, J.G., Hanan, B.B., Blichert-Toft, J., Koppers, A.A., Plank, T., Staudigel, H., 2008. One hundred million years of mantle geochemical history suggest the retiring of mantle plumes is premature. Earth and Planetary Science Letters 275, 285-295.

Labrosse, S., 2002. Hotspots, mantle plumes and core heat loss. Earth and Planetary Science Letters 199, 147-156. 
Lay, T., Hernlund, J., Buffett, B., 2008. Core-mantle boundary heat flow. Nature Geosciences 1, 25-32.

Leng, W., Gurnis, M., 2012. Shape of thermal plumes in a compressible mantle with depth-dependent viscosity. Geophysical Research Letters 39.

Leng, W., Zhong, S., 2008. Controls on plume heat flux and plume excess temperature. Journal of Geophysical Research: Solid Earth 113.

Li, M., Zhong, S., 2017. The source location of mantle plumes from 3d spherical models of mantle convection. Earth and Planetary Science Letters $478,47-57$.

Li, M., Zhong, S., 2019. Lateral motion of mantle plumes in 3d geodynamic models. Geophysical Research Letters 46, 4685-4693.

Mittelstaedt, E., Tackley, P.J., 2006. Plume heat flow is much lower than cmb heat flow. Earth and Planetary Science Letters 241, 202 - 210. doi https: //doi.org/10.1016/j.epsl.2005.10.012.

Montelli, R., Nolet, G., Dahlen, F., Masters, G., 2006. A catalogue of deep mantle plumes: New results from finite-frequency tomography. Geochemistry, Geophysics, Geosystems 7.

Morgan, J., 1978. Rodriguez, darwin, amsterdam, ... a second type of hotspot island. Journal of Geophysical Research 83, 5355-5360.

Morgan, W.J., 1972. Plate motions and deep mantle convection. Geological Society of America Memoirs 132, 7-22. 
Morgan, W.J., 1981. 13. hotspot tracks and the opening of the atlantic and indian oceans. The oceanic lithosphere 7, 443.

Muller, R., Cannon, J., Qin, X., Watson, R., Gurnis, M., Williams, S., Pfaffelmoser, T., Seton, M., Russell, S., Zahirovic, S., 2018. Gplates: Building a virtual earth through deep time. Geochemistry, Geophysics, Geosystems 19, 2243-2261.

Nakiboglu, S., Lambeck, K., 1980. Deglaciation effects on the rotation of q the earth. Geophysical Journal International 62, 49-58. doi:10.1111/j. 1365-246X.1980.tb04843.x.

O’Neill, C., Müller, D., Steinberger, B., 2005. On the uncertainties in hot spot reconstructions and the significance of moving hot spot reference frames. Geochemistry, Geophysics, Geosystems 6.

Parnell-Turner, R., White, N., Henstock, T., Murton, B., Maclennan, J., Jones, S.M., 2014. A continuous 55-million-year record of transient mantle plume activity beneath iceland. Nature Geoscience 7, 914.

Poore, H., White, N., Jones, S., 2009. A neogene chronology of iceland plume activity from v-shaped ridges. Earth and Planetary Science Letters 283, $1-13$.

Portnyagin, M., Savelyev, D., Hoernle, K., Hauff, F., Garbe-Schonberg, D., 2008. Mid-cretaceous hawaiian tholeiites preserved in kamchatka. Geology 36, 903-906.

Putirka, K.D., 2005. Mantle potential temperatures at hawaii, iceland, and the mid-ocean ridge system, as inferred from olivine phenocrysts: Evidence 
for thermally driven mantle plumes. Geochemistry, Geophysics, Geosystems 6 .

Ricard, Y., Richards, M., Lithgow-Bertelloni, C., Le Stunff, Y., 1993. A geodynamic model of mantle density heterogeneity. Journal of Geophysical Research: Solid Earth 98, 21895-21909. doi:10.1029/93JB02216.

Richards, M.A., 1991. Hotspots and the case for a high viscosity lower mantle, in: Glacial Isostasy, Sea-Level and Mantle Rheology. Springer, pp. 571-587.

Richards, M.A., Griffiths, R.W., 1988. Deflection of plumes by mantle shear flow: experimental results and a simple theory. Geophysical Journal International 94, 367-376.

Rudolph, M.L., Lekić, V., Lithgow-Bertelloni, C., 2015. Viscosity jump in earth's mid-mantle. Science 350, 1349-1352.

Rudolph, M.L., Zhong, S.J., 2014. History and dynamics of net rotation of the mantle and lithosphere. Geochemistry, Geophysics, Geosystems 15, 3645-3657.

Sandwell, D.T., Smith, W.H., 1997. Marine gravity anomaly from geosat and ers 1 satellite altimetry. Journal of Geophysical Research: Solid Earth 102, 10039-10054.

Sleep, N.H., 1990. Hotspots and mantle plumes: Some phenomenology. Journal of Geophysical Research: Solid Earth 95, 6715-6736.

Steinberger, B., Antretter, M., 2006. Conduit diameter and buoyant rising 
speed of mantle plumes: Implications for the motion of hot spots and shape of plume conduits. Geochemistry, Geophysics, Geosystems 7.

Steinberger, B., Calderwood, A.R., 2006. Models of large-scale viscous flow in the earth's mantle with constraints from mineral physics and surface observations. Geophysical Journal International 167, 1461-1481.

Steinberger, B., O'Connell, R.J., 1998. Advection of plumes in mantle flow: implications for hotspot motion, mantle viscosity and plume distribution. Geophysical Journal International 132, 412-434.

Steinberger, B., O'Connell, R.J., 2000. Effects of mantle flow on hotspot motion. The History and Dynamics of Global Plate Motions , 377-398.

Tackley, P., 2008. Modelling compressible mantle convection with large viscosity contrasts in a three-dimensional spherical shell using the yin-yang grid. Physics of the Earth and Planetary Interiors 171, 7-18.

Tackley, P.J., 1998. Self-consistent generation of tectonic plates in threedimensional mantle convection. Earth and Planetary Science Letters 157, 9-22.

Tackley, P.J., 2000. Self-consistent generation of tectonic plates in timedependent, three-dimensional mantle convection simulations. Geochemistry, Geophysics, Geosystems 1.

Tackley, P.J., King, S.D., 2003. Testing the tracer ratio method for modeling active compositional fields in mantle convection simulations. Geochemistry, Geophysics, Geosystems 4. doi:10.1029/2001GC000214. 
Tarduno, J., Bunge, H.P., Sleep, N., Hansen, U., 2009. The bent hawaiianemperor hotspot track: Inheriting the mantle wind. Science 324, 50-53.

Tarduno, J.A., Duncan, R.A., Scholl, D.W., Cottrell, R.D., Steinberger, B., Thordarson, T., Kerr, B.C., Neal, C.R., Frey, F.A., Torii, M., et al., 2003. The emperor seamounts: Southward motion of the hawaiian hotspot plume in earth's mantle. Science 301, 1064-1069.

Tetley, M., Williams, S., Gurnis, M., Flament, N., Müller, D., 2019. Constraining absolute plate motions since the triassic. Journal of Geophysical Research: Solid Earth doi:10.1029/2019JB017442.

Torsvik, T.H., Doubrovine, P.V., Steinberger, B., Gaina, C., Spakman, W., Domeier, M., 2017. Pacific plate motion change caused the hawaiianemperor bend. Nature Communications 8, 15660.

Turcotte, D., Schubert, G., 2014. Geodynamics. Cambridge University Press. Wang, S., Yu, H., Zhang, Q., Zhao, Y., 2018. Absolute plate motions relative to deep mantle plumes. Earth and Planetary Science Letters 490, 88-99.

Whitehead, J.A., 1982. Instabilities of fluid conduits in a flowing earth-are plates lubricated by the asthenosphere? Geophysical Journal International $70,415-433$.

Whittaker, J., Afonso, J., Masterton, S., Müller, R., Wessel, P., Williams, S., Seton, M., 2015. Long-term interaction between mid-ocean ridges and mantle plumes. Nature Geoscience 8, 479-483. 
Williams, S., Flament, N., Muller, R., Butterworth, N., 2015. Absolute plate motions since 130 ma constrained by subduction zone kinematics. Earth and Planetary Science Letters 418, 66-77.

Wilson, D.S., Hey, R.N., 1995. History of rift propagation and magnetization intensity for the cocos-nazca sspreading center. Journal of Geophysical Research: Solid Earth 100, 10041-10056. doi:10.1029/95JB00762.

Wilson, J.T., 1963. A possible origin of the hawaiian islands. Canadian Journal of Physics 41, 863-870.

Wilson, J.T., 1965. Evidence from ocean islands suggesting movement in the earth. Phil. Trans. R. Soc. Lond. A258, 45-165.

Zhong, S., 2006. Constraints on thermochemical convection of the mantle from plume heat flux, plume excess temperature, and upper mantle temperature. Journal of Geophysical Research: Solid Earth 111.

Zhong, S., 2009. Migration of tharsis volcanism on mars caused by differential rotation of the lithosphere. Nature Geosciences 2, 19.

Zhong, S., Zhang, N., Li, Z.X., Roberts, J.H., 2007. Supercontinent cycles, true polar wander, and very long-wavelength mantle convection. Earth and Planetary Science Letters 261, 551-564.

Zhong, S., Zuber, M.T., Moresi, L., Gurnis, M., 2000. Role of temperaturedependent viscosity and surface plates in spherical shell models of mantle convection. Journal of Geophysical Research: Solid Earth 105, 1106311082 . 
Table 1: Non-dimensional and dimensional model parameters

\begin{tabular}{|c|c|c|}
\hline Parameter & $\begin{array}{l}\text { Non-dim. } \\
\text { value }\end{array}$ & Dim. value \\
\hline Surface temperature $\left(\mathrm{T}_{t o p}\right)$ & 0.12 & $255 \mathrm{~K}$ \\
\hline Basal temperature $\left(\mathrm{T}_{b o t}\right)$ & 1.12 & $2240-2645 \mathrm{~K}$ \\
\hline Mantle thickness (D) & 1 & $2890 \mathrm{~km}$ \\
\hline Reference thermal expansivity $\left(\alpha_{0}\right)$ & 1 & $3 \times 10^{-5} \mathrm{~K}^{-1}$ \\
\hline Reference density $\left(\rho_{0}\right)$ & 1 & $4400 \mathrm{~kg} \mathrm{~m}^{-3}$ \\
\hline Reference diffusivity $\left(\kappa_{0}\right)$ & 1 & $1 \times 10^{-6} \mathrm{~m}^{2} \mathrm{~s}^{-1}$ \\
\hline Reference heat capacity $\left(c_{p 0}\right)$ & 1 & $715 \mathrm{~J} \mathrm{~kg}^{-1} \mathrm{~K}^{-1}$ \\
\hline Reference viscosity $\left(\eta_{0}\right)$ & 1 & $1 \times 10^{22} \mathrm{~Pa} \mathrm{~s}$ \\
\hline Internal heating rate $(H)$ & $40-50$ & $7.54-9.43 \times 10^{-12} \mathrm{~W} \mathrm{~kg}^{-1}$ \\
\hline Activation energy $\left(E_{a}\right)$ & 8 & $142 \mathrm{~kJ} \mathrm{~mol}^{-1}$ \\
\hline Activation volume $\left(V_{a}\right)$ & 3 & $13.8 \mathrm{~cm}^{3} \mathrm{~mol}^{-1}$ \\
\hline Maximum viscosity cut-off & $10^{4}$ & $10^{26} \mathrm{~Pa} \mathrm{~s}$ \\
\hline Viscosity factor below $660 \mathrm{~km}$ depth & 30 & \\
\hline Yield stress gradient for all materials $\left(\mathrm{d} \sigma_{Y}\right)$ & $2.34 \times 10^{6}$ & $1088 \mathrm{~Pa} \mathrm{~m}^{-1}$ \\
\hline Oceanic lithosphere surface yield stress $\left(\sigma_{Y_{0, o c}}\right)$ & $2-200 \times 10^{4}$ & $27-270 \mathrm{MPa}$ \\
\hline Weak-crust surface yield stress (Model $5, \sigma_{Y_{0, w c}}$ ) & $1 \times 10^{4}$ & $13 \mathrm{MPa}$ \\
\hline Weak-crust thickness (Model 5) & 0.005 & $14 \mathrm{~km}$ \\
\hline Continental interior surface yield stress $\left(\sigma_{Y_{0, \text { cont }}}\right)$ & $7 \times 10^{5}$ & $932 \mathrm{MPa}$ \\
\hline Continental interior viscosity factor & 100 & \\
\hline Continental interior buoyancy number $\left(B_{\text {cont }}\right)$ & -0.32 & $-150 \mathrm{~kg} \mathrm{~m}^{-3}$ \\
\hline Continental interior thickness & 0.0692 & $200 \mathrm{~km}$ \\
\hline Continental belt surface yield stress $\left(\sigma_{Y_{\text {belt }}}\right)$ & $3 \times 10^{5}$ & $400 \mathrm{MPa}$ \\
\hline Continental belt viscosity factor & 50 & \\
\hline Continental belt buoyancy number $\left(B_{\text {belt }}\right)$ & -0.4 & $-188 \mathrm{~kg} \mathrm{~m}^{-3}$ \\
\hline Continental belt thickness & 0.0432 & $125 \mathrm{~km}$ \\
\hline Basal thermochemical layer buoyancy number $\left(B_{l l s v p}\right)$ & 0.25 & $117 \mathrm{~kg} \mathrm{~m}^{-3}(2.7 \%)$ \\
\hline Basal thermochemical layer initial thickness & 0.17 & $500 \mathrm{~km}$ \\
\hline Basal thermochemical layer viscosity factor & 10 & \\
\hline
\end{tabular}


(a)

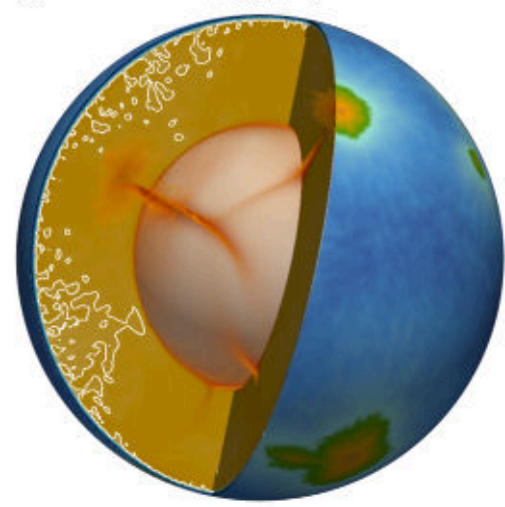

(c)

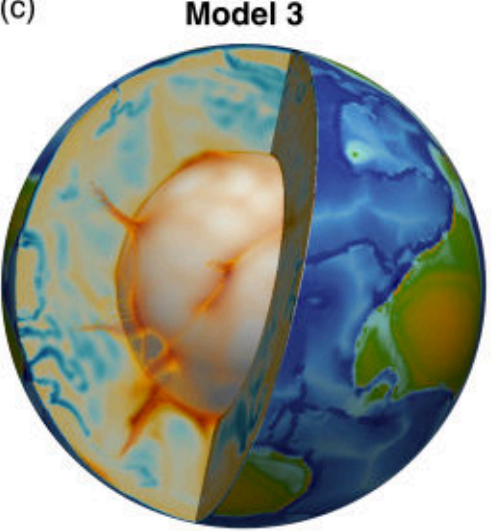

(e)

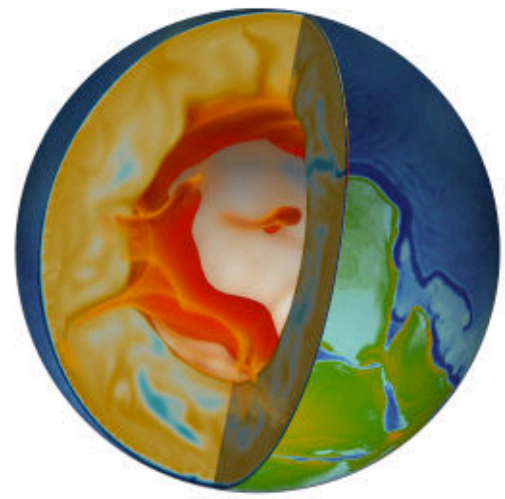

(b)
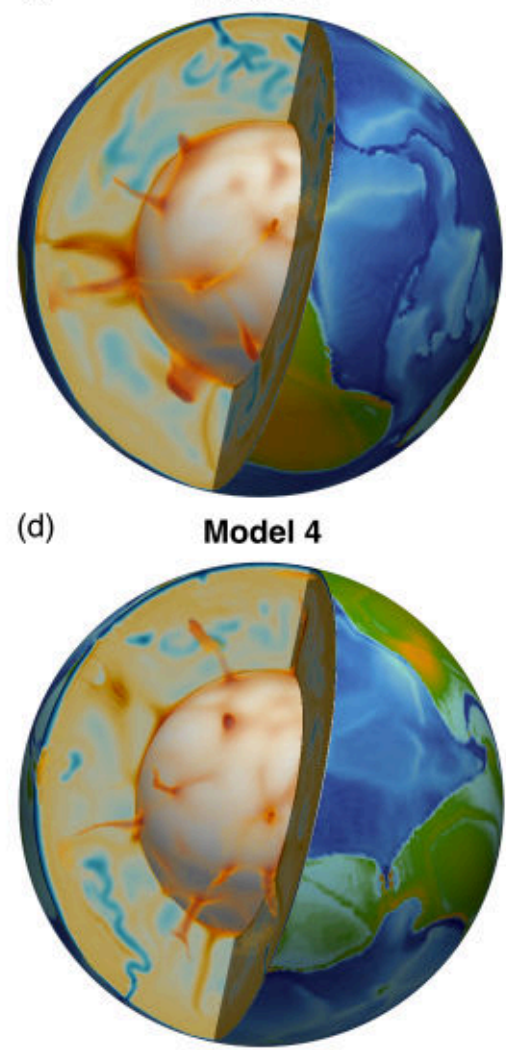

Temperature (K)

Topography (km)

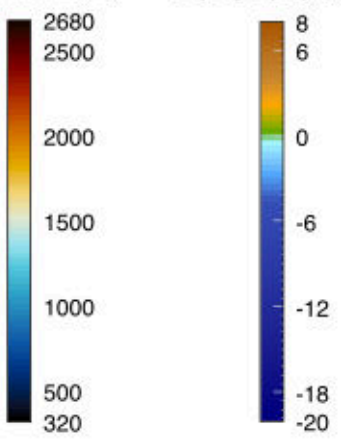

Figure 1: 3D snapshots of (a) Model 1, (b) Model 2, (c) Model 3, (d) Model 4 and (e) Model 5. Temperature is shown in the interior of the shells and topography at their surface. The white isotherm on (a) highlights small-scale convection. The red isosurface on (e) delineates basal thermochemical heterogeneities. 

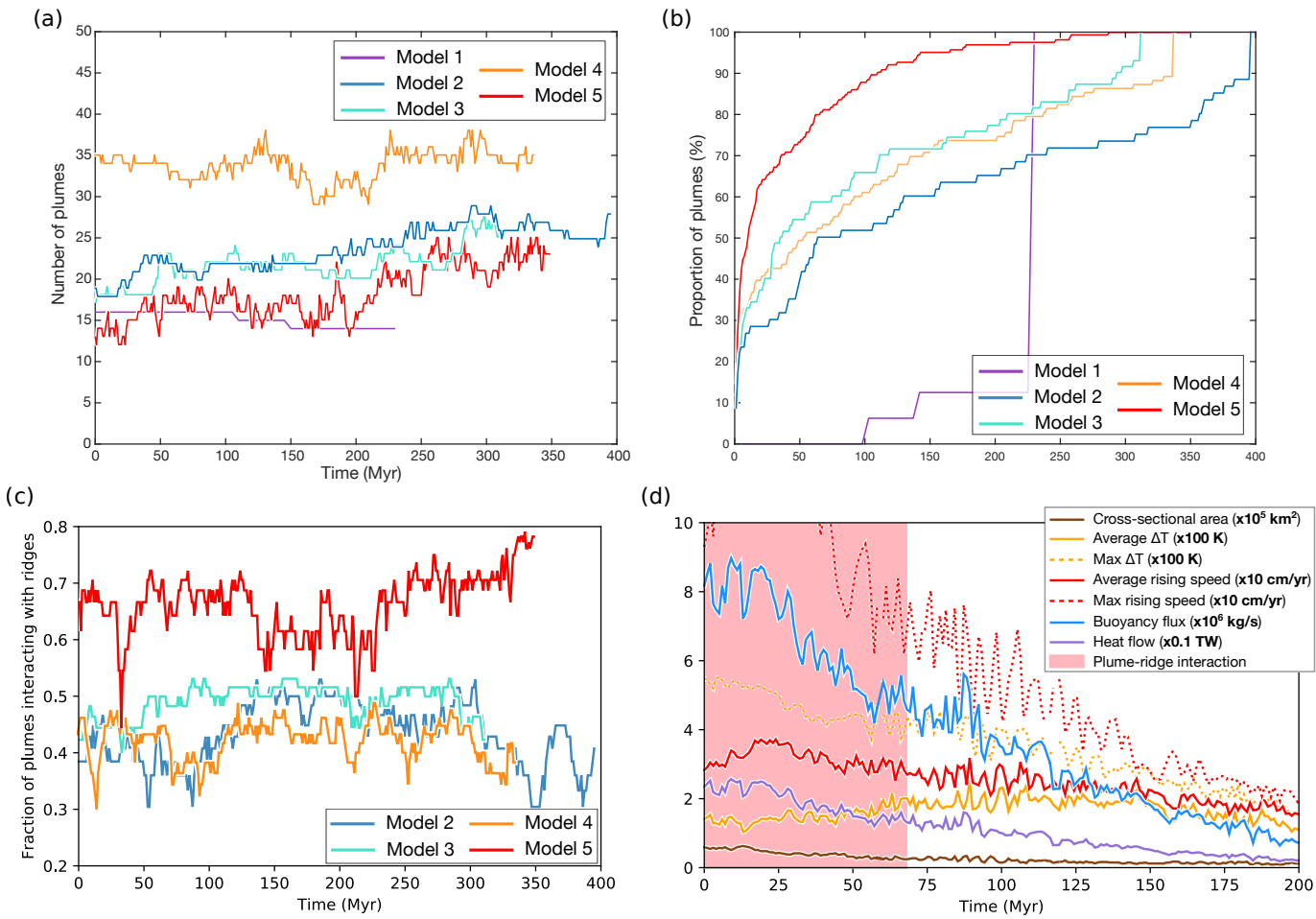

Figure 2: Evolution, at $350 \mathrm{~km}$ depth, of (a) the number of plumes, (b) the cumulative lifetime of plumes and (c) the fraction of plumes interacting with ridges. (d) Temporal evolution of plume characteristics for Plume ID 6 in Model 2 (Fig. S3(a) and (b)): crosssectional area (brown), average (orange) and maximum (orange, dashed) temperature excess, average (red) and maximum (red, dashed) buoyant rising speed, buoyancy flux (blue) and heat flux (purple). The units of each curve is listed in the figure key. The duration of plume-ridge interaction is highlighted by the pink area. 
(a)

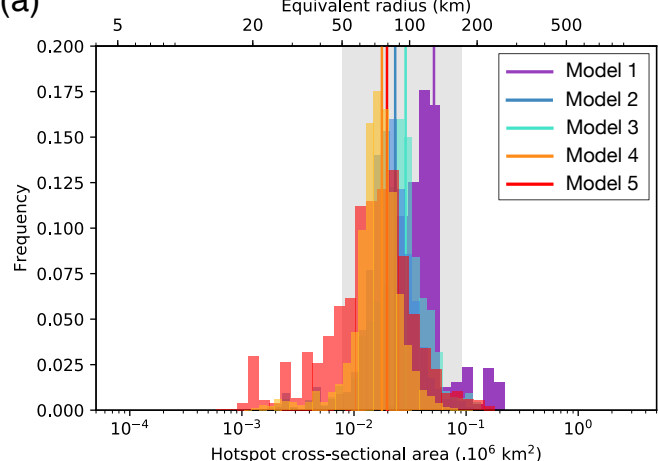

(c)

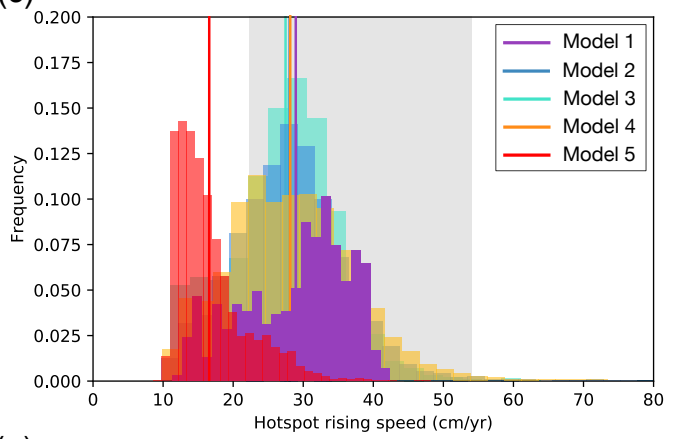

(e)

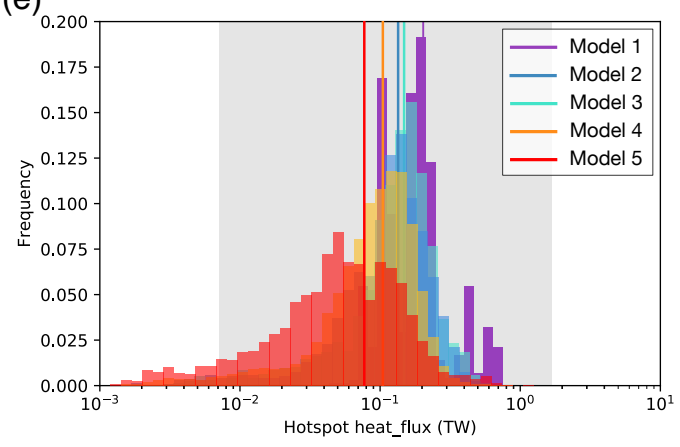

(b)

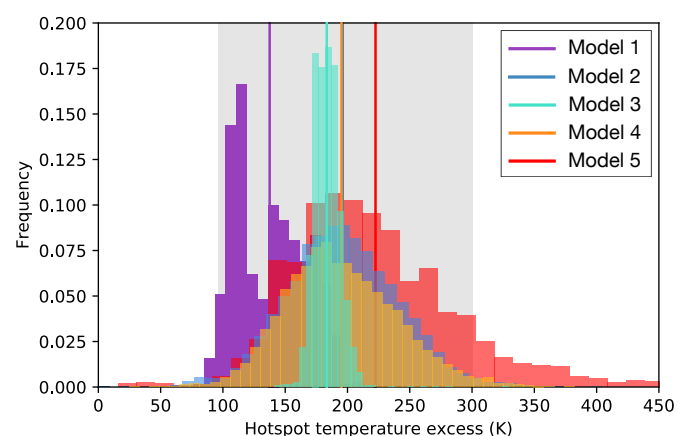

(d)

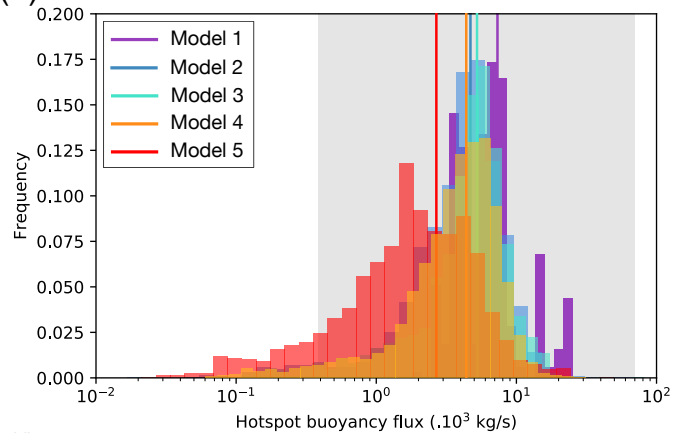

(f)

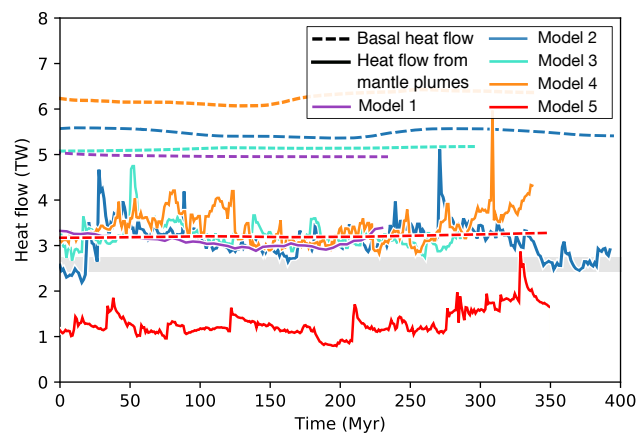

Figure 3: Distribution of (a) the radius, (b) the excess temperature, (c) the buoyant rising speed, (d) the buoyancy flux and (e) the heat flow of mantle plumes for all models at $350 \mathrm{~km}$ depth. Temporal evolution of (f) the core and plume heat flow in all models at $350 \mathrm{~km}$ depth. Spikes in plume heat flow correspond to the occasional birth of highlyvigorous plumes. The grey areas highlight the range of observational values for each plume characteristic (see text for details). 
(a)

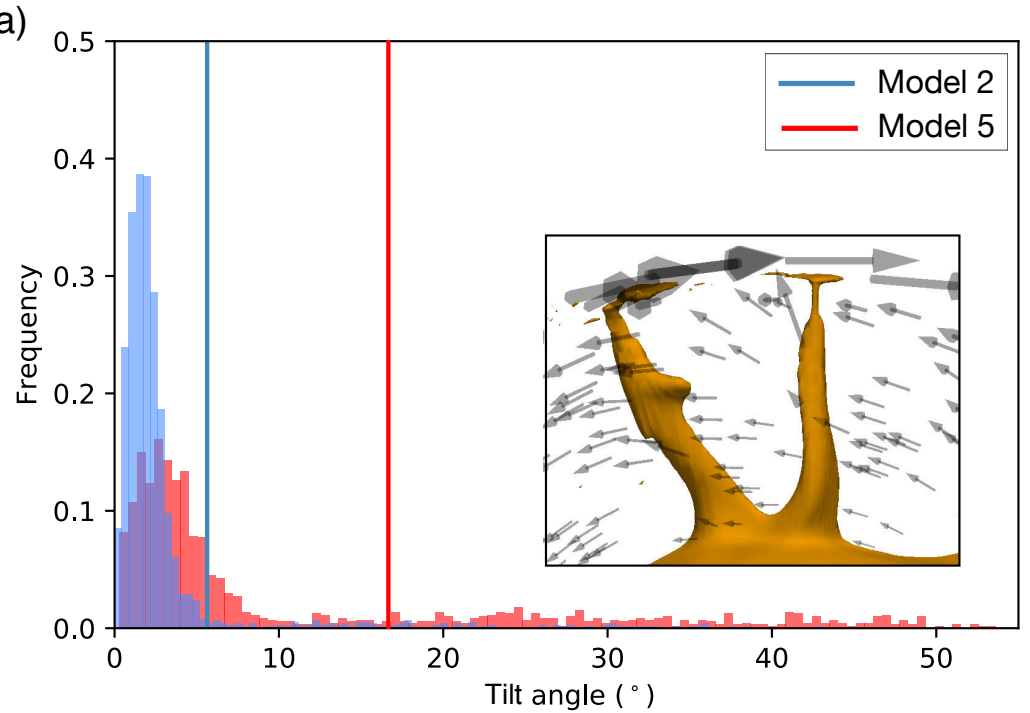

(b)

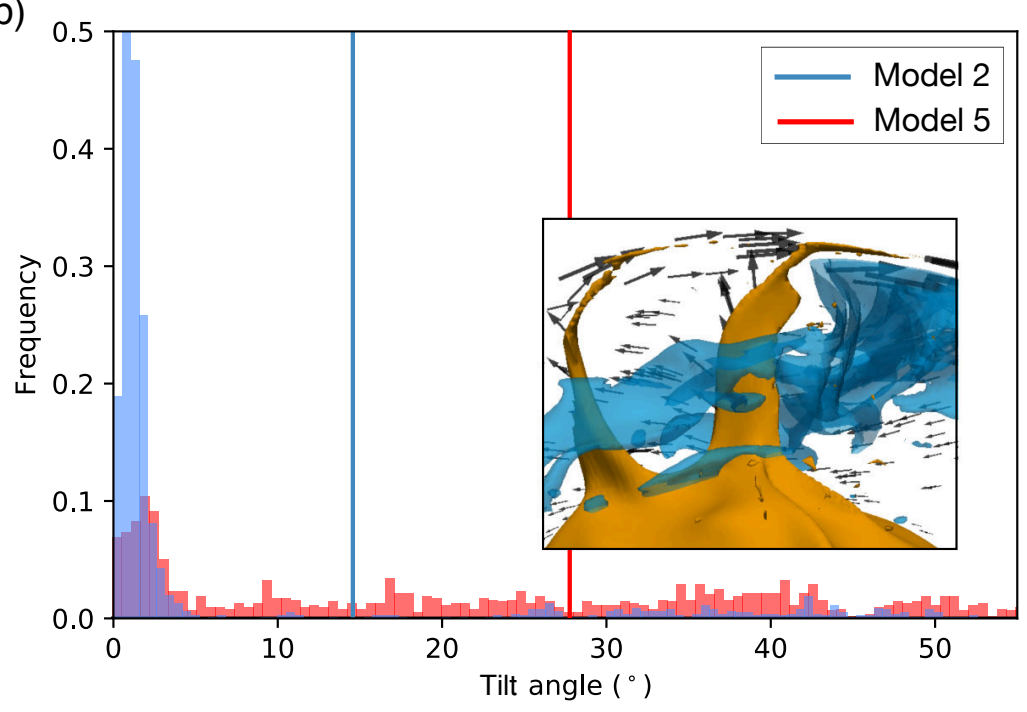

Figure 4: (a) Upper-lower mantle (350-1000 km depth) and (b) upper mantle (150-670 km depth) plume tilt angle distribution for Models 2 and 5 . The average tilt angle is shown as a vertical line. Insets show (a) near vertical and (b) tilted conduits (orange isotherm) in Model 5. Transparent black arrows show the direction of mantle flow. In (b) mantle flow deflects plume conduits in the vicinity of subducting lithosphere (transparent blue isotherm). Note that plume deflection mainly occurs in the uppermost mantle. 
Table 2: Key model parameters for all models (w.c. = weak crust, depth dep. = depth-dependent thermal expansivity, Continent ages $=$ ages of their initial configuration). Average plateness and surface mobility of all models. Modeled average and standard deviation of surface $\left(\mathbf{v}_{\mathbf{r m s}}\right)$, mantle horizontal $\left(\mathbf{v}_{\mathbf{m}}\right)$, mantle net rotation $(\mathrm{NR})$ and plume absolute $\left(\mathbf{v}_{\mathbf{h a}}\right)$ and relative $\left(\mathbf{v}_{\mathbf{h r}}\right)$ velocities in the upper (UM, between 150 and $410 \mathrm{~km}$ depth) and the lower (LM, between $670 \mathrm{~km}$ depth and the CMB) mantle. Mobility and plateness are dimensionless.

\begin{tabular}{|c|c|c|c|c|c|c|c|}
\hline Parameter & Model 1 & Model 2 & Model 3 & Model 4 & Model 5 & Doubrovine & Tetley et al. \\
\hline & & & & & & et al. (2012) & $(2019)$ \\
\hline Yield stress (MPa) & no yielding & 48 & 27 & 48 & 61 (w.c.) & & \\
\hline Thermal expansivity & depth dep. & depth dep. & depth dep. & constant & depth dep. & & \\
\hline LLSVPs & no & no & no & no & yes & & \\
\hline Continents & no & $80 \mathrm{Ma}$ & $80 \mathrm{Ma}$ & $80 \mathrm{Ma}$ & $200 \mathrm{Ma}$ & & \\
\hline Plateness & & 0.90 & 0.77 & 0.84 & 0.87 & & \\
\hline Mobility & & 1.29 & 1.69 & 1.62 & 1.60 & & \\
\hline Surface $\mathbf{v}_{\mathbf{r m s}}(\mathrm{cm} / \mathrm{yr})$ & 0.002 & $2.90 \pm 0.85$ & $3.32 \pm 0.22$ & $3.79 \pm 0.60$ & $5.04 \pm 1.83$ & $2-6$ & $1.5-4.8$ \\
\hline Mean UM $\mathbf{v}_{\mathbf{m}}(\mathrm{cm} / \mathrm{yr})$ & $2.34 \pm 0.82$ & $3.19 \pm 0.57$ & $2.77 \pm 0.32$ & $3.60 \pm 0.57$ & $4.85 \pm 1.52$ & & \\
\hline Mean LM $\mathbf{v}_{\mathbf{m}}(\mathrm{cm} / \mathrm{yr})$ & $0.85 \pm 0.25$ & $0.91 \pm 0.26$ & $0.74 \pm 0.15$ & $1.01 \pm 0.23$ & $1.23 \pm 0.35$ & & \\
\hline Average NR ( $\left.{ }^{\circ} / \mathrm{Myr}\right)$ & $0.001 \pm 0.0003$ & $0.039 \pm 0.014$ & $0.031 \pm 0.013$ & $0.039 \pm 0.016$ & $0.029 \pm 0.009$ & $0.13-0.53$ & $0.05-0.11$ \\
\hline Mean UM $\mathbf{v}_{\mathbf{h a}}(\mathrm{cm} / \mathrm{yr})$ & $0.57 \pm 0.45$ & $1.80 \pm 1.13$ & $1.74 \pm 0.78$ & $2.22 \pm 0.82$ & $2.40 \pm 0.77$ & $1.12 \pm 0.31$ & $2.07 \pm 0.80$ \\
\hline Mean UM $\mathbf{v}_{\mathbf{h r}}(\mathrm{cm} / \mathrm{yr})$ & $0.63 \pm 0.64$ & $1.55 \pm 1.58$ & $1.61 \pm 1.18$ & $2.20 \pm 1.28$ & $2.22 \pm 1.15$ & $0.87 \pm 0.35$ & $1.46 \pm 1.07$ \\
\hline Mean LM $\mathbf{v}_{\mathbf{h a}}(\mathrm{cm} / \mathrm{yr})$ & $0.39 \pm 0.51$ & $1.32 \pm 0.56$ & $1.05 \pm 0.32$ & $1.79 \pm 0.90$ & $2.04 \pm 1.25$ & & \\
\hline Mean LM $\mathbf{v}_{\mathbf{h r}}(\mathrm{cm} / \mathrm{yr})$ & $0.44 \pm 0.68$ & $1.02 \pm 0.83$ & $0.77 \pm 0.47$ & $1.66 \pm 1.37$ & $2.01 \pm 1.90$ & & \\
\hline
\end{tabular}



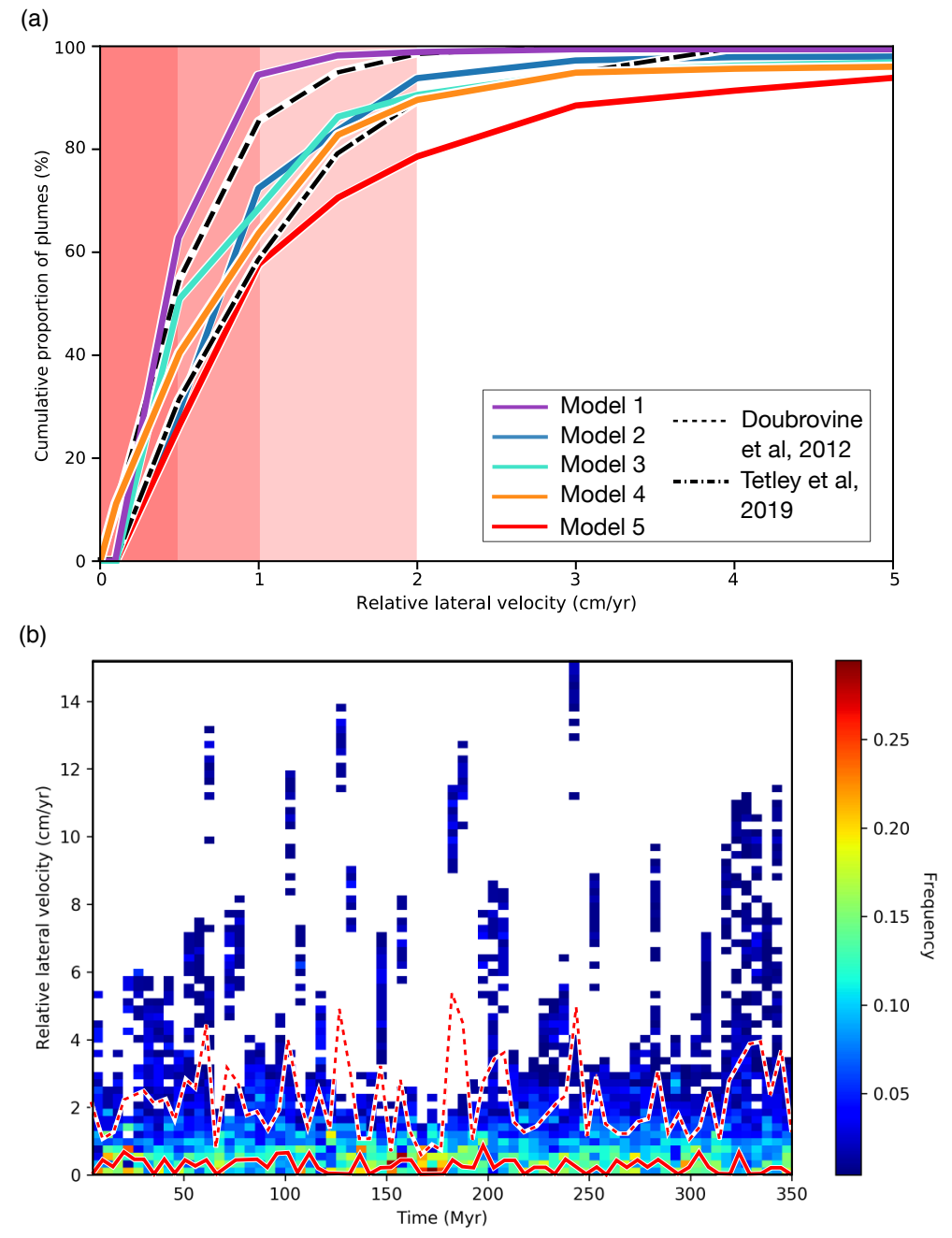

Figure 5: (a) Time-averaged cumulative distribution of relative plume velocities in all models and as estimated for Earth by Doubrovine et al. (2012) and OptAPM1-M16 of Tetley et al. (2019). The transparent red background rectangles highlight the cumulative proportion of plumes moving at less than $0.5,1$ and $2 \mathrm{~cm} \mathrm{yr}^{-1}$. (b) Density plot of the temporal evolution of upper mantle RMS pair-wise lateral relative velocity distribution between mantle plumes in Model 5. Relative velocities are calculated in $5 \mathrm{Myr}$ intervals. The thick red line is the temporal evolution of the mode of relative mantle plume velocities. The dashed red line is the temporal evolution of the average relative velocities between mantle plumes. 


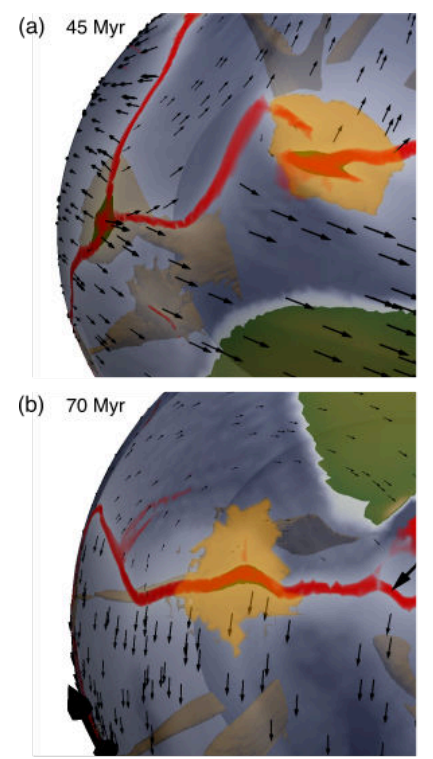

(c)
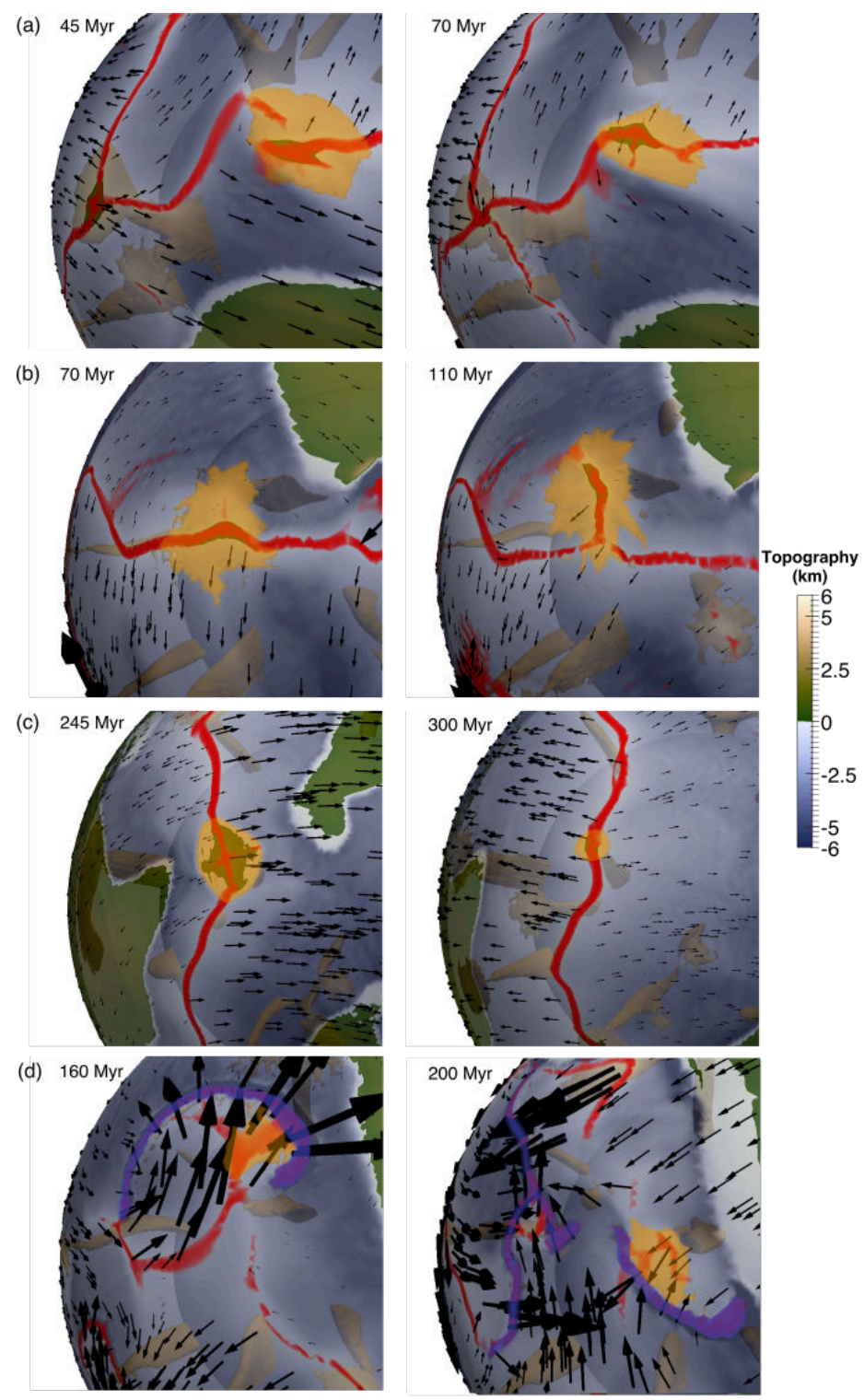

Figure 6: Four cases of ridge-plume interactions in Model 2: (a) plume ponding below a stable ridge (b) ridge-jump in the vicinity of a plume, (c) ridge-propagation induced by a plume, and (d) backarc-plume interaction. Surface topography is outlined as a transparent field. Arrows represent surface velocities. Plume isotherms are seen by transparency in orange. The thermal trail of considered plumes are highlighted in brighter orange. Ridges are in red and subduction zones are in transparent blue. The camera is fixed for each temporal evolution. 
(a)
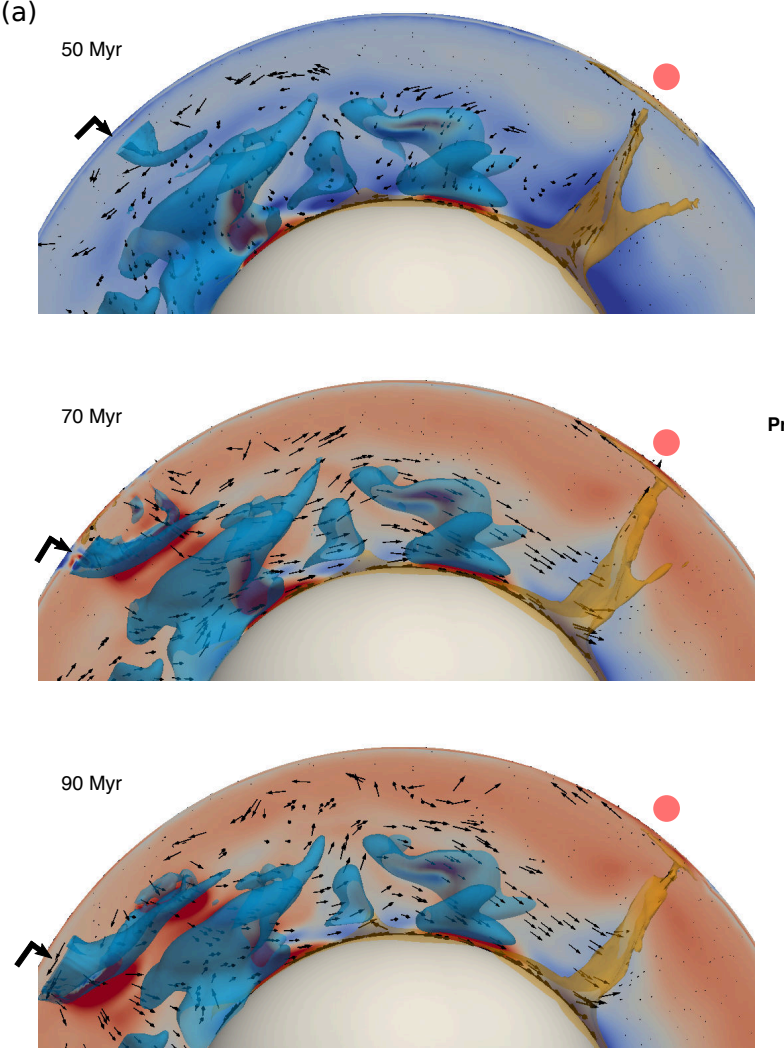

(b)

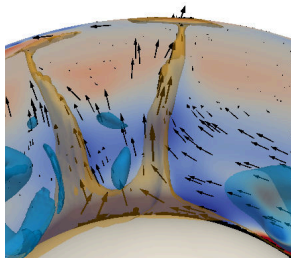

$60 \mathrm{Myr}$

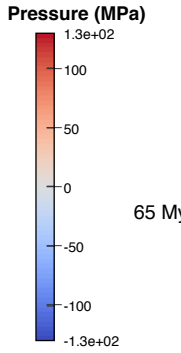

$65 \mathrm{Myr}$

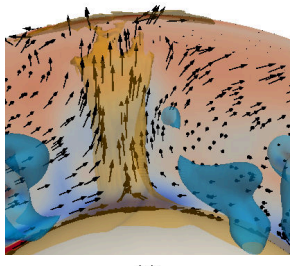

$70 \mathrm{Myr}$

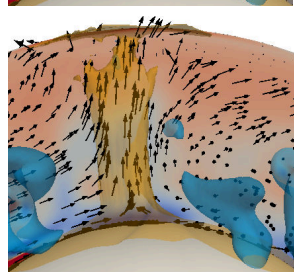

Figure 7: Examples of pressure-gradient-induced plume drifts in Model 2. Mantle plumes are highlighted by orange transparent isotherms and subducting lithosphere is shown as transparent blue isotherms. The velocity field is shown as black arrows. In (a), the position of the plume is indicated at each timestep with a red circle. Subduction (the thick black arrow shows the location of the trench) initiates on the left-hand-side, which results in far-field compression and horizontal lower mantle flow directed towards the plume. (b) Merging of two mantle plumes starting from the base of the mantle and propagating upwards. The camera is fixed. 
(a)

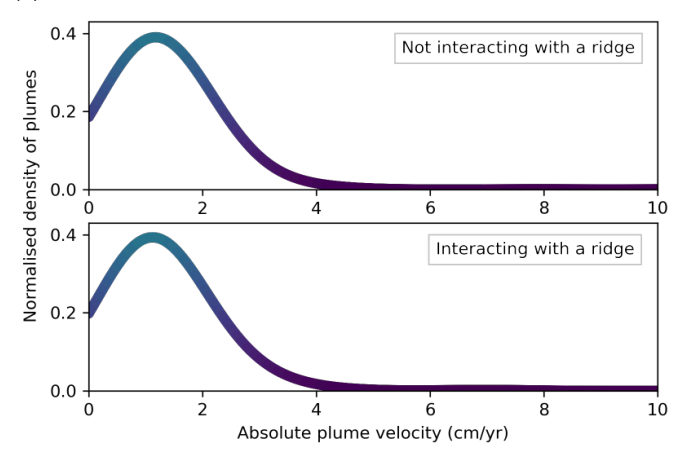

(c)

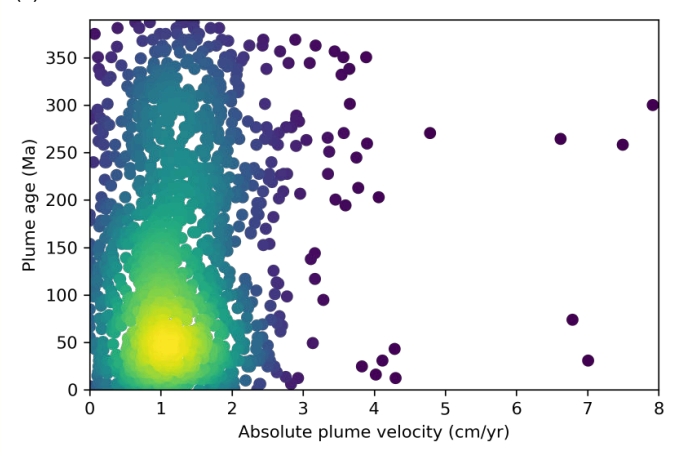

(e)

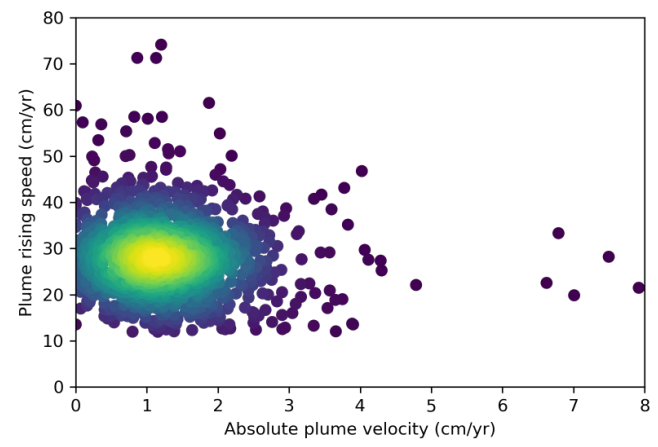

(b)

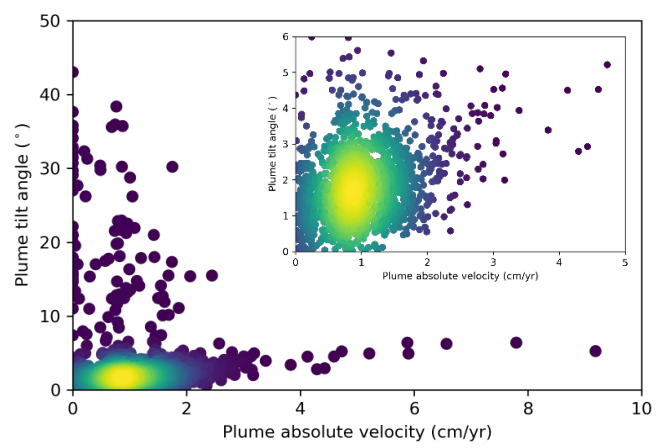

(d)

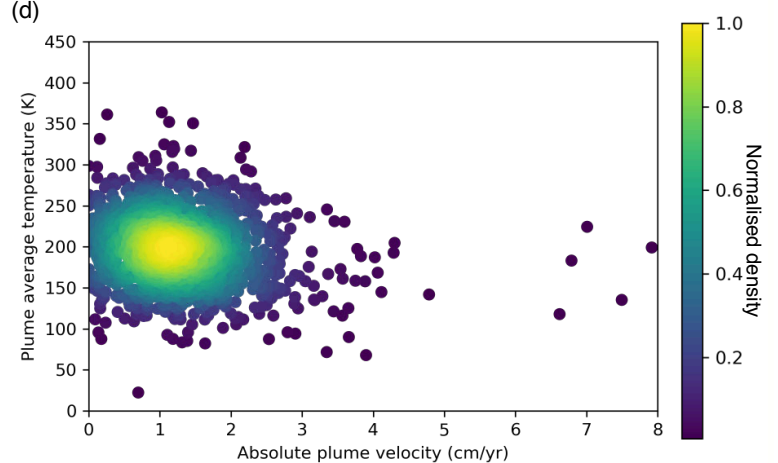

(f)

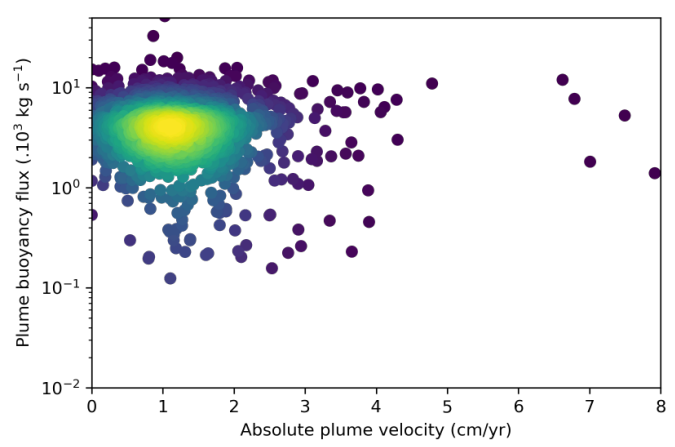

Figure 8: Distribution of (a) plumes interacting (bottom panel) or not (top panel) with ridges, (b) plume tilt angle between 150 and $670 \mathrm{~km}$ depth, (c) plume age, (d) plume temperature excess, (e) plume rising speed and (f) plume buoyancy flux versus plume absolute velocity for Model 2. The color scale shows the normalised density of mantle plumes on each plot. The inset on (b) shows a closeup view on the largest density of plumes of that plot. 